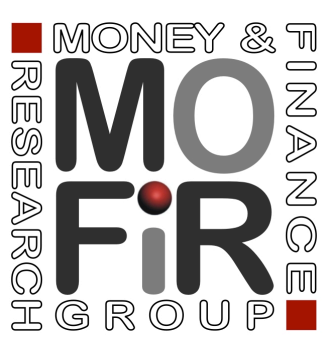

\title{
INTERNATIONAL ASSET ALLOCATIONS AND CAPITAL FLOWS: \\ THE BENCHMARK EFFECT
}

Claudio Raddatz Sergio L. Schmukler Tomás Williams

Working paper no. 141 


\title{
International Asset Allocations and Capital Flows: The Benchmark Effect
}

Claudio Raddatz

Sergio L. Schmukler

Tomás Williams*

August 2017

\begin{abstract}
We study different channels through which well-known benchmark indexes impact asset allocations, capital flows, asset prices, and exchange rates across countries, using unique monthly micro-level data of benchmark compositions and mutual fund investments during 1996-2014. We exploit different events and the presence of countries in multiple benchmarks to study the impact of benchmarks. We find that movements in benchmarks appear to have important effects on equity and bond mutual fund portfolios, including passive and active funds. The effects persist even after controlling for other relevant variables, such as time-varying industry-level factors, country-specific effects, and macroeconomic fundamentals. Exogenous, pre-announced changes in benchmarks impact asset allocations, capital flows, and abnormal returns in asset prices and exchange rates. These systemic effects occur not just when the benchmark changes are announced, but also later on when they become effective. By impacting country allocations, benchmarks explain apparently counterintuitive movements in capital flows and aggregate prices.
\end{abstract}

\section{JEL Classification Codes: F32, F36, G11, G15, G23}

Keywords: benchmark indexes, contagion, coordination mechanism, ETFs, international asset prices, international portfolio flows, mutual funds

\footnotetext{
${ }^{*}$ This paper is forthcoming in the Journal of International Economics. For financial support, we thank the Hong Kong Institute for Monetary Research and the World Bank Research Department, Knowledge for Change Program, and Latin American and the Caribbean Chief Economist Office. We are grateful to Juan José Cortina, Sebastián Cubela, Julián Kozlowski, Matías Moretti, and Lucas Núñez for excellent research assistance. We received very useful comments from Matías Braun, Fernando Broner (the editor), Guillermo Calvo, Eduardo Cavallo, Nathan Converse, Ganga Darbha, Charles Engel, Eduardo Fernandez Arias, Jose de Gregorio, Gaston Gelos, Bernardo Guimaraes, Marcel Fratzscher, Harald Hau, Lance Kent, Robert Lavigne, Steve Lawrence, Philip Lane, Pedro Matos, Gian Maria Milesi-Ferretti, Guillermo Ordoñez, Ana Pavlova, Luis Serven, Ilhyock Shim, Hyun Song Shin, Carlos Vegh, Frank Warnock, Jialin $\mathrm{Yu}$, Stefan Zeume, two anonymous referees, and participants at presentations held at the Annual Meeting of the Chilean Economic Society, Barcelona GSE Jamboree, Bank of Japan, BIS-Bank of Canada-World Bank Public Investors Conference, CEMP-CIEPS-HKUST IEMS Workshop, Central Bank of Argentina, Columbia University, Cornell University, CREI-Universitat Pompeu Fabra, Fourth Symposium on Emerging Financial Markets: China and Beyond, Global Financial Stability Conference, Honk Kong Institute for Monetary Research, IMF, IADB-Central Banks Conference, Ninth CEPR Annual Workshop on Macroeconomics of Global Interdependence, LACEA Annual Meetings, Latin Finance Network, London Business School, NIPFP, Sao Paulo School of Economics, Universidad Adolfo Ibañez, Universidad de San Andres, University of Virginia Darden School of Business, and World Bank. The views expressed here do not necessarily represent those of the International Monetary Fund or the World Bank. Raddatz is with the International Monetary Fund. Schmukler is with the World Bank Research Department. Williams is with the George Washington University. The views expressed here do not necessarily represent those of the International Monetary Fund or the World Bank. Email addresses: craddatzkiefer@imf.org; sschmukler@worldbank.org; tomaswilliams@gwu.edu.
} 


\section{Introduction}

Several papers argue that benchmark indexes are important for equity prices and how managers allocate their portfolios across firms. ${ }^{1}$ In this paper, we show how benchmarks can matter in the international context, not only for asset allocations but also for capital flows, asset prices, and exchange rates. In doing so, we depart from the typically studied effects of macroeconomic fundamentals on cross-country investment decisions, which have been the focus of the international finance literature. ${ }^{2}$

The "benchmark effect" refers to various channels through which prominent international equity and bond market indexes (such as, the MSCI Emerging Markets Index or the MSCI World Index) affect asset allocations, capital flows, and prices across countries. Theoretical models predict that the investment strategy of these funds is pinned down by the composition of their benchmark indexes (Chakravorti and Lall, 2004; Basak and Pavlova, 2012; Deniz and Pinheiro, 2015). Therefore, changes in the country weights of a popular benchmark can trigger a similar rebalancing among the funds that track it and result in sizeable movements in financial markets. ${ }^{3}$ But the implications of this effect on different variables is not trivial and has not been systematically documented using cross-country data.

According to the capital asset pricing (CAPM) model, if benchmark indexes perfectly reflected market weights, their components were atomistic, and their weights were adjusted instantaneously, investors would hold these indexes and the benchmarks themselves would not

\footnotetext{
${ }^{1}$ Several papers study the importance of benchmarks, focusing primarily on the performance evaluation of mutual funds relative to their benchmarks, in particular, on whether active management pays (Lehmann and Modest, 1987; Sharpe, 1992; Wermers, 2000; Cremers and Petajisto, 2009; Sensoy, 2009; Busse et al., 2014; Cremers et al., 2016). A related literature focuses on how benchmark redefinitions affect stock returns, pricing, and liquidity (Harris and Gurel, 1986; Shleifer, 1986; Chen et al., 2004; Barberis et al., 2005; Greenwood, 2005; Hau et al., 2010; Hau, 2011; Vayanos and Wooley, 2011, 2016; Claessens and Yafeh, 2012; Faias et al., 2012; Bartram at al., 2015; Chang et al., 2015).

${ }^{2}$ Some examples of the many papers on the topic are Di Giovanni (2005), Kraay et al. (2005), Lane and Milesi-Ferreti (2007), Antràs and Caballero (2009), Martin and Taddei (2013), Reinhardt et al. (2013), and Gourinchas and Rey (2014).

${ }^{3}$ The extent to which fund portfolios are linked to their benchmarks depends on several factors, including the manager's risk aversion and the correlation among the assets in the benchmark portfolio (Roll, 1992; Brennan, 1993; Disyatat and Gelos, 2001). Moreover, mutual funds declare prospectus benchmarks but they need not follow them (Cremers and Petajisto, 2009). Furthermore, the number of assets in benchmark indexes is much larger than that held in mutual fund portfolios (Didier et al., 2013), which suggests that some funds do not fully replicate these indexes.
} 
generate any distortion. ${ }^{4}$ But benchmark indexes are imperfect and do not necessarily hold the market portfolio. There are many indexes covering overlapping sets of countries, so their composition and the decisions of the companies that construct them to include different countries in different benchmarks can matter for global asset allocations. Moreover, individual countries tend to have non-negligible weights and can distort different indexes when included/excluded. As a growing number of international mutual funds and other institutional investors follow popular benchmarks more passively to cut costs, evaluate and discipline fund managers, increase transparency, and provide simple investment vehicles (such as, index funds and exchange-traded funds or ETFs), these effects are expected to increase and need to be understood and quantified. ${ }^{5}$

A clear practical example of the benchmark effect took place when Israel was moved from the MSCI Emerging Markets Index to the World Index (composed of developed markets). Although the upgrade was announced in advance and occurred because Israel's fundamentals had improved (Business Week, 2010), we show that Israel faced significant capital reallocations, capital outflows, and negative returns when the upgrade became effective due to the behavior of funds following these indexes. These effects have prompted some to argue for South Korea and Taiwan not to be upgraded to developed market status (Bloomberg, 2014). Similar discussions have emerged with the actual and potential upgrades of Portugal (1997), Greece (2001), Qatar (2014), the United Arab Emirates (U.A.E.) (2014), and China (2015) and the downgrades of Venezuela (2006), Argentina (2009), and Greece (2013) (Financial Times, 2013a,b,c; BIS, 2014; The Economist, 2014a). One reason for the effect on capital flows is that a country's inclusion (exclusion) in a benchmark index should drive managers with index-tracking strategies to rebalance their portfolios and direct flows into (out of) that country (The Economist, 2012).

In this paper, we systematically study how benchmarks affect international financial markets. First, we study to what extent movements in benchmark weights map into movements in the actual country weights ("weights") of the funds that declare that benchmark. We exploit

\footnotetext{
${ }^{4}$ Still, price discovery might be hampered, which can exacerbate co-movement across assets (Wurgler, 2011).

${ }^{5}$ Other problems can arise due to the use of benchmark weights to overcome agency problems, but these issues are not examined in the empirical analysis of this paper.
} 
the timing of changes in benchmarks and the presence of a country in multiple benchmarks, to shed light on whether the evidence is consistent with a causal link between benchmarks and portfolio allocations. Second, we show the consequences that the relation between mutual fund weights and benchmark weights has for mutual fund flows, and quantify the importance of benchmarks for capital flows. Third, we use upgrades and downgrades of countries to study how aggregate asset prices and exchange rates respond to benchmark changes. Fourth, we use several key cases to illustrate how benchmark changes can impact countries in different ways.

To conduct the research, we compile a novel dataset of detailed portfolio allocations across countries by a large number of international mutual funds that we match with the allocations of the benchmarks they follow. The dataset covers the period from January 1996 to September 2014 and contains international mutual funds based in major financial centers around the world investing in at least two countries (i.e., it excludes country funds). A total of 2,837 equity and 838 bond funds are in the sample. These equity and bond funds collectively had 1,052 and 293 billion U.S. dollars in assets under management in December 2011, respectively. ${ }^{6}$

Our results show that benchmarks have statistically and economically significant effects on the allocations and capital flows of mutual funds across countries. Mutual funds follow benchmarks rather closely. For example, a 1 percent increase in a country's benchmark weight results on average in a 0.7 percent increase in the weight of that country for the typical mutual fund that follows that benchmark. Explicit indexing funds seem to follow benchmarks almost one-for-one, generating some mechanical effects in allocations and capital flows. Although the most active funds in our sample are less connected to the benchmarks, they still seem to be significantly influenced by their behavior, with about 50 percent of their allocations explained by benchmarks. The effects on mutual fund portfolios appear relevant even after controlling for time-varying industry allocations and country-specific or macroeconomic factors, usually mentioned in the finance and international finance literatures. The results do not seem to be just the consequence of common shocks affecting both mutual fund weights and benchmark weights

\footnotetext{
${ }^{6}$ Mutual funds are offered to investors in different ways, for example, in different currencies and with different costs. These funds have the same portfolios but many times are counted as separate funds. In our data, we just count them once to avoid repeating the portfolios, but we report their aggregated assets.
} 
(via returns) or reverse causality (which could occur as mutual funds reallocate their portfolio, exerting pressure on returns and benchmark weights). Instead, exogenous events that modify indexes appear to affect not only benchmark but also mutual fund weights.

By influencing the asset allocations of mutual funds, benchmarks seem to have systemic effects. In particular, benchmarks can explain nearly 40 percent of capital flows from mutual funds, with this percentage increasing to 70 percent in times of large exogenous changes to benchmarks. Moreover, large benchmark changes (such as upgrades and downgrades of countries) are associated with abnormal returns in asset prices and exchange rates around those events. These abnormal returns behave as predicted by the mutual fund flows; they become positive (negative) when inflows to (outflows from) a country are expected. Notably, these effects are present both during the announcement and effective dates of these changes. For example, the cumulative asset price differential returns are 1.5 percent around the announcement date and 3.5 percent around the effective date. Our results suggest that, through the reallocations they trigger, benchmark changes affect prices beyond the information content of upgrades/downgrades.

The rest of the paper is organized as follows. Section 2 describes the data. Section 3 studies the effect of benchmarks on mutual fund asset allocations. Section 4 analyzes the relation between asset allocations and capital flows, and the effects of benchmarks on these flows. Section 5 studies how asset prices and exchange rates react around benchmark changes. Section 6 presents some case studies that further illustrate the effects on capital flows and asset prices. Section 7 concludes.

\section{Data}

Our main database consists of: (i) country weights or weights, $w_{i c}$, which are the country portfolio allocations of international mutual funds (those investing in several countries); (ii) benchmark weights, $w_{i c}^{B}$, which are the country allocations in the relevant benchmarks; (iii) mutual fund-specific information, such as its assets, returns, and relevant benchmarks; (iv) 
country-specific information, such as stock and bond market index returns. ${ }^{7}$ The sub-index $i$ refers to funds, $c$ to countries, and the supra-index $B$ to benchmarks. For the final database, we clean the raw data and merge data from several sources, some of which had not been previously used or matched in the literature. This database covers the period from January 1996 to July 2012 and constitutes an unbalanced panel. We use some additional data (described later in the paper) to study the reactions of capital flows and asset prices, covering newer episodes up to 2014.

Our database contains 2,837 equity funds and 838 bond funds, including global, global emerging, and regional funds, whose total net assets (TNAs, $A_{i t}$ ) have increased significantly over time. ${ }^{8}$ Moreover, funds in our combined dataset capture an important part of the assets held by the industry of international funds. For example, our sample of U.S.-domiciled equity funds had 442 billion dollars in TNAs, while the Investment Company Institute (ICI) reports that, during the same period, U.S. (non-domestic) international funds held 1.4 trillion dollars including the numerous country funds that we exclude due to our interest on country weights. Similar estimates for Europe from the European Fund Asset Management Association (EFAMA) show that our sample accounts for approximately 53 percent of the international funds in this region. Explicit indexing funds (mostly ETFs) represent a fast growing but still relatively small share of the industry. By also including closet indexing funds, both the level and growth rate of the funds that closely track benchmark indexes increases significantly. ${ }^{9}$

Our two main sources for country portfolio allocations of international mutual funds are EPFR (Emerging Portfolio Fund Research) and Morningstar Direct (MS). Both sources include dead and live mutual funds. The data from EPFR are at a monthly frequency, and include openend equity and bond funds classified according to their geographical investment scope. Global funds invest anywhere in the world, global emerging funds only in emerging countries, and

\footnotetext{
${ }^{7}$ Benchmark weights $w_{i c}^{B}$ are fund-specific because each fund chooses its benchmark. We thus denote it with sub-index $i$. The same applies to other benchmark characteristics such as benchmark returns.

${ }^{8}$ In 2011, the equity (bond) funds in our sample had 1.2 trillion (303 billion) U.S. dollars in TNAs (Online Appendix Figure 1). Equity funds are domiciled around the entire world but most of the funds are located in Canada, France, Ireland, Luxembourg, the United States (U.S.), and the United Kingdom (U.K.). Most bond funds are domiciled in Denmark, Germany, Ireland, Israel, Italy, Luxembourg, the U.S., and the U.K. ${ }^{9}$ The trends exhibited by the share of total assets of ETFs in our sample also appear in data on U.S. mutual funds from the Investment Company Institute (ICI), which does not identify closet indexing funds.
} 
regional funds in groups of countries within a specific geographical region. ${ }^{10}$ The data also comprise portfolios of ETFs. We use only funds with information for at least one year. For each fund $i$ and each month $t$, the data contain information on the share of the fund's assets invested in each of 124 countries and cash, as well as its TNAs. We also have information on static characteristics, for example, the asset class, domicile, whether a fund is an ETF, its strategy (passive or active), and, crucially, its declared benchmark. We complement these data with information on the funds' net asset value (NAV) from Datastream and MS. We match the funds from these different databases.

We use similar data from MS to complement the EPFR data. That is, we use data on country weights, TNAs, NAVs, and static fund characteristics for additional international mutual funds not included in EPFR with at least one year of monthly data. ${ }^{11}$ This increases importantly the cross-sectional coverage of our final dataset. MS reports country weights in only 52 countries and does not contain data on cash allocations..$^{12}$ The combination of the two databases provides us with an extensive cross-sectional and time-series coverage of funds (Online Appendix Table 1). MS contains a large number of funds after 2007 but very few in earlier years, while EPFR has a more balanced number of funds dating back to $1996 .{ }^{13}$ In addition, we use stock and bond market country indexes from J.P. Morgan and MSCI to compute the country returns, $R_{c t}$, which we impute to each fund's investment in each country (we do not have information on the actual returns of each fund in each country). ${ }^{14}$ This information comes from Datastream and MSCI.

\footnotetext{
${ }^{10}$ While global funds theoretically can invest anywhere in the world, a large proportion of them track the MSCI World Index, which only has developed countries as constituents. A minor proportion of these funds track the MSCI All Country World Index, which contains both developed and emerging countries.

${ }^{11}$ Although MS includes funds that report quarterly, almost 90 percent of the original MS sample reports allocations on a monthly frequency.

${ }^{12}$ In our estimations, we only use country allocations and, thus, do not include the residual category of other countries (those not explicitly reported in the EPFR or MS databases) nor cash.

${ }^{13}$ In our consolidated database we kept the country coverage of MS (52 countries) and adapted the EPFR database to this format, lumping countries outside these 52 in a residual category called "other equity" (also present in MS). We have also performed robustness tests for the impact of this change for the EPFR database. The results are qualitatively similar.

${ }^{14}$ The correlation between the actual fund returns and the computed returns using country returns is 89 percent, which shows that country returns are a good proxy for individual returns. Some of the small unexplained part is due to differences in the country returns and security level returns, but it might also be due to the fact that the data have a small residual category ("other equity/bonds") that we cannot assign to any particular country given the information available.
} 
In addition to our data on fund country weights, we also use data on the country benchmark weights and returns of several major benchmark indexes $\left(R_{i t}^{B}\right)$. We obtain these data directly from FTSE, J.P. Morgan, and MSCI through bilateral agreements, and indirectly through MS for indexes produced by Dow Jones, Euro Stoxx, and S\&P. The benchmarks indexes we use have different scope and are listed in Online Appendix Table 2. For each of the benchmark indexes in MS and MSCI, we collect data on price returns, gross returns, and net returns. We rely heavily on the MSCI benchmark indexes because 86 percent of our data on equity mutual funds declare to follow them..$^{15}$ Moreover, we gather daily data from Datastream to analyze the impact of benchmark changes in asset prices and foreign exchange rates.

To match the data on international mutual funds with the benchmark indexes, we assign to each fund the index declared in its prospectus. For funds with no declared index, we impute the benchmark assigned to it by industry analysts, as reported by MS, although the results reported below are similar when considering only funds that explicitly declare a benchmark. We were able to match 88 percent of the equity funds and 18 percent of the bond funds in our database. The reduced matching of bond funds with their benchmarks is not because of matching problems but for lack of information on the detailed portfolio composition of their benchmark indexes. ${ }^{16,17} \mathrm{We}$ do not use the rest of the funds because it is not clear whether the missing information is due to the fund not following a benchmark or following a benchmark unknown to us (for dead funds, this information was impossible to retrieve). ${ }^{18}$ Our final database consists of an unbalanced panel, where each observation is a country-fund-time observation containing the percentage of TNAs invested in a particular country by a mutual fund, the

\footnotetext{
${ }^{15}$ Some funds follow a linear combination of two or more indexes. We use that combination as their benchmark.

${ }^{16}$ Most bond funds follow J.P. Morgan bond indexes. However, within this family we could only get access to the detailed composition of the EMBI+, EMBI+ Global, and EMBI+ Global Diversified.

${ }^{17}$ There is no agreement on how to assign benchmarks. Papers use the declared benchmark, the one assigned by analysts, and/or the one that yields the smallest deviation from the fund portfolio (Cremers and Petajisto, 2009; Sensoy, 2009; Cremers et al., 2013; Jiang et al., 2014; Busse et al., 2014).

${ }^{18}$ Having access to the benchmarks makes the matching relatively straightforward given that funds have increasingly reported their benchmarks. For instance, among the funds covered by EPFR, 28 percent of equity funds did not report a benchmark in 1996, while 5 percent did not do so in July 2012. Our matching for equity funds is rather complete because only 9 percent of equity funds in our sample do not report (or are assigned) a benchmark. For bond funds, that number is 16 percent.
} 
percentage allocation of that same country at the same time for the assigned benchmark, plus fund-specific information.

We also classify funds according to how active the fund manager is, following Cremers and Petajisto (2009) but using country weights instead of security weights. In particular, we classify funds as "explicit indexing," "closet indexing," "mildly active," and "truly active" funds. ${ }^{19}$ Explicit indexing funds are either ETFs or passive funds. Closet indexing funds do not declare to be passive but behave similarly to explicit indexing funds. Mildly and truly active funds are those that deviate importantly from their self-declared benchmarks. Specifically, for each fund we first compute its active share each month and then take the average over time as a time-invariant measure of a fund's deviation from its benchmark allocations. This measure gives the average percentage of a fund's portfolio that deviates from its benchmark. ${ }^{20}$. We then define closet indexing funds as those that on average have an active share within two standard deviations of the active share of explicit indexing funds. Funds not belonging to the explicit indexing or closet indexing groups are classified into mildly active (truly active) if they are in the lower part (upper) of the distribution of the active share measure (using the median active share). ${ }^{21}$

\section{Benchmarks and asset allocations}

To study systematically how mutual fund weights respond to benchmark weights, we estimate panel regressions that relate a fund's country weight to its benchmark weights, including different fixed effects that capture various types of shocks.

We start by estimating the parameters of the following specification:

$$
w_{i c t}=\theta_{i c}+\theta_{i t}+\alpha_{1} w_{i c t}^{B}+\varepsilon_{i c t},
$$

where $w_{i c t}$ is the weight for fund $i$, in country $c$, and at time $t, w_{i c t}^{B}$ is the respective benchmark weight that fund $i$ follows; $\theta_{i c}$ and $\theta_{i t}$ are fund-country and fund-time fixed effects. The fundcountry and fund-time fixed effects account for persistent differences in the weight that each

\footnotetext{
${ }^{19}$ One possible alternative to this measure is the root mean square error (RMSE), which penalizes large deviations from the benchmark index. But the measure of active share we use has been the standard in the literature on mutual fund activism since Cremers and Petajisto (2009), in part because it shows the percentage of the portfolio that is invested outside the benchmark.

${ }^{20}$ More formally, it is defined as $A S_{i t}=\frac{1}{2} \sum_{c}\left|w_{i c t}-w_{i c t}^{B}\right|$.

${ }^{21}$ The results are robust to the selection of benchmarks, where we assign the minimum active share benchmark to each fund.
} 
fund holds in each country and for the shocks that funds receive at each point in time (such as, redemptions and injections or changes in the cash or other positions). The errors, $\varepsilon_{i c t}$, are clustered at the benchmark-time level, which allows for unobserved correlation among all funds that declare a common benchmark. ${ }^{22}$ We run these regressions pooling all funds and separating them by how active the fund manager is. 23,24

The results using all equity funds (Table 1, Panel A) show that, although there is variation in the estimated coefficients for benchmark weights $\left(\alpha_{1}\right.$ in Equation (1)) across groups, all types of funds seem to follow benchmarks to a significant extent. For the group of all funds the coefficient obtained in the weight regressions is 0.77 . The coefficients decline monotonically for more active fund managers. For example, explicit indexing funds move almost one-to-one with benchmarks and the percentage of the variance explained is also higher relative to all funds. Estimates for closet indexing funds are close to those of explicit indexing ones, with an estimated coefficient of 0.92 , and similar R-squared estimates. In fact, they are much closer to explicit indexing than to mildly active funds, whose estimated coefficient is 0.82 . Importantly, the results indicate that benchmark weights are significantly associated with the mutual fund portfolio allocations even for the most active funds in the sample. The coefficient for the truly active funds is 0.5 , which is significant statistically and economically. Moreover, a significant part of the variance is captured in the different estimations. ${ }^{25}$

The results for bond funds are qualitatively similar (Table 1, Panel B). Although explicit indexing funds do not move one-to-one with benchmarks, the explained variation by the benchmarks is still 99 percent when including the fixed effects. This might be due to a small sample problem given that we have few explicit indexing bond funds in our sample. Moreover, fund managers might invest differently in bonds than in equities due to the different nature of

\footnotetext{
22 The errors in our specification are correlated at the fund-time level because at each point in time an increase in the weight of a country in a fund's portfolio requires the decline of other countries. Part of this mechanical correlation is removed by excluding residual countries and cash, but it is still likely to be present. The results are qualitatively similar is we use instead the standard errors proposed by Driscoll and Kraay (1998).

${ }^{23}$ Results using log weights instead of weights are very similar to those reported here.

${ }^{24}$ Online Appendix 1 discusses a possible portfolio decision framework for the interpretation of $\alpha_{1}$.

${ }^{25}$ In unreported estimations with no fixed effects we find that benchmark weights explain around 40 percent of the variation in country weights.
} 
these markets, which might explain the somewhat smaller coefficients for bond funds in general. For example, Raddatz and Schmukler (2012) show that bond funds hold more cash as a buffer against shocks, which could explain a smaller reaction to benchmarks.

Our results are very similar when controlling for both industry-level and country-level omitted variables. In particular, to control for the possibility that funds follow the industry given the use of relative performance to evaluate managers against their peers, we add the median weight across a specified segment of mutual funds to the previous regressions. ${ }^{26}$ Furthermore, we exploit the fact that countries are included in more than one benchmark at the same time to account for the possibility that country-specific factors (like macroeconomic fundamentals) can play a role in cross-country investments. Namely, we use the variation across benchmarks for the same country-time observation. ${ }^{27}$ We control for the omitted country fundamentals by adding a set of country-time fixed effects, absorbing non-parametrically all possible time-varying, countryspecific shocks. The results are qualitatively similar when using macroeconomic variables as controls instead of country-time fixed effects. Figure 1 illustrates the results including countrytime fixed effects.

A technical concern comes from the persistence of country and benchmark weights, which we address by running the regression in differences:

$$
\Delta w_{i c t}=\theta_{i c}+\theta_{i t}+\alpha_{2} \Delta w_{i c t}^{B}+\varepsilon_{i c t} .
$$

The results suggest that, although the coefficients estimated for $\alpha_{2}$ are a bit smaller (Table 1), they are similar to those estimated in levels. ${ }^{28}$

Another potential difficulty in relating benchmark weights and mutual fund weights is that relative returns could drive some of the results. In particular, exogenous fluctuations in returns (a common shock) could affect both variables simultaneously through the buy-and-hold

\footnotetext{
${ }^{26}$ For segments, we use: Asia excluding Japan, BRIC, Emerging Europe, Europe, Europe Middle East and Africa, Global, Global Emerging, Latin America, and the Pacific.

${ }^{27}$ There is a significant amount of variation in changes in benchmark weights for a given country at a particular point in time (Online Appendix Figure 2, Panel A).

${ }^{28}$ In unreported robustness exercises, we estimated other dynamic specifications with several lags and an error correction term. The economic significance of those additional terms tends to be small relative to the contemporaneous change in benchmark weights, not changing our conclusions.
} 
part of the portfolio. Moreover, reverse causality could arise if benchmark weights responded through returns to movements in mutual fund weights, instead of the other way around.

The potential problems that relative returns can introduce are, however, ameliorated by the fact that benchmark indexes are built and adjusted frequently using exogenous criteria (related, among other things, to the inclusion/exclusion of securities, changes in the security loadings, and the reclassification of countries into different groups), independent on the actions of fund managers (Online Appendix 2). Moreover, because benchmarks have to sum up to 100 percent, all countries in a benchmark are affected by the exogenous changes in one particular country. Though most exogenous changes imply small reallocations, others are large.

We can effectively isolate the buy-and-hold from the exogenous components in each benchmark weight. In the absence of exogenous reallocations, the benchmark weight of country $c$ at time $t, w_{c t}^{B}$, would just follow a buy-and-hold pattern, $w_{c t}^{B}=w_{c t-1}^{B}\left(R_{c t} / R_{t}^{B}\right)$, where $R_{c t}$ and $R_{t}^{B}$ are the return of the country and the return of the benchmark, respectively. With exogenous changes related to changes in the underlying securities, upgrades or downgrades of countries, and other changes decided exogenously by index providers, $E_{c t}^{B}$, benchmark weights follow:

$$
w_{c t}^{B}=w_{c t-1}^{B}\left(R_{c t} / R_{t}^{B}\right)+E_{c t}^{B} .
$$

By using both of these components separately, we analyze how mutual funds respond to benchmark changes that come from relative returns and from exogenous events.

This decomposition is possible because relative returns are not the only important determinant of changes in benchmark weights, even when on average benchmark weights move almost one-to-one with relative returns (Table 2). In fact, after controlling for benchmarkcountry, benchmark-time, and country-time fixed effects (the identification comes exclusively from the time variation within a benchmark-country), the $R^{2}$ of the various regressions are between 0.3 and 0.6 at the monthly level. ${ }^{29} \mathrm{~A}$ main reason for this result are the regular revisions

\footnotetext{
${ }^{29}$ Including more lags of log changes in benchmark weights or relative returns do not have much effect on the relative return coefficients, and the economic and statistical significance of the other lags diminish rapidly.
} 
to the indexes, leading to frequent re-weighting of all the countries. ${ }^{30}$ These are exogenous reallocations that are independent of the performance of a country.

To formally study how regular exogenous changes to the benchmark indexes affect mutual fund weights, we substitute the benchmark weight in Equation (2) for its two components from Equation (3) and estimate the parameters of the following specification:

$$
\Delta w_{i c t}=\theta_{i c}+\theta_{i t}+\alpha \Delta\left[w_{i c t-1}^{B}\left(R_{c t} / R_{i t}^{B}\right)\right]+\beta \Delta E_{i c t}^{B}+\varepsilon_{i c t} .
$$

We test whether the coefficient for the exogenous shocks is significantly different from zero. This approach exploits all the variation in benchmark weights that is unrelated to the buy-andhold component to identify the possible causal impact. The results show that the exogenous component has a significantly positive effect on mutual fund weights (Table 3). As expected, the relation is decreasing for more active funds, but even active fund allocations are positively correlated with this component of benchmark weights.

We then focus on large events. Because these large events are usually pre-announced, finding evidence of an impact on allocations when they take place provides evidence that actual, contemporaneous benchmark weights matter for international mutual funds. However, we face the problem that there are few events of whole country upgrades/downgrades to exploit, so we include episodes of large changes in the intensive margin to increase our statistical power. We identify these "exogenous event times/episodes" using the fact that changes in MSCI indexes are released in the months of February, May, August, and November. We compute the exogenous component during these months as in Equation (3) and assume that finding a large exogenous component (below the $25^{\text {th }}$ and above the $75^{\text {th }}$ percentile of the sample distribution) in any of these months is likely due to the announcement of an exogenous change in the index.

In particular, we test whether the mutual fund weights respond to benchmark weights differently in days with exogenous events relative to other days by estimating:

$$
\Delta w_{i c t}=\theta_{i c}+\theta_{i t}+\alpha_{N} \Delta w_{i c t}^{B} D_{N}+\alpha_{E} \Delta w_{i c t}^{B} D_{E}+\varepsilon_{i c t},
$$

\footnotetext{
${ }^{30}$ Another potential reason is that because we do not know the return of a country within each benchmark and instead use a common country return imputed to all benchmarks that include that country, the residual term could capture these differences. Nonetheless, this residual is probably small due to the bottom-up approach. That is, benchmarks in the same country category (developed, emerging, frontier) will tend to have the same stocks for each constituent country and the country returns will be similar across them.
} 
where $D_{N}$ is a dummy indicating normal times and $D_{E}$ is a dummy indicating times with large exogenous events. Finding that $\alpha_{E}<\alpha_{N}\left(\alpha_{E}>\alpha_{N}\right)$ would mean that the relation between benchmark weights and country weights weakens (strengthens) in months when benchmark weights are largely driven by exogenous episodes. Alternatively, not being able to reject the hypothesis that $\alpha_{E}=\alpha_{N}$ means that the exogenous movements in benchmark weights matter for country weights as much as those driven by relative returns. The results show that the link between mutual fund weights and benchmark weights remains strong during exogenous episodes (Table 3). In several instances, funds do not tend to respond very differently to exogenous events or other changes in benchmark weights.

Lastly, we test how equity mutual funds responded to a particular MSCI methodological change event that implied an overall index redefinition (also exploited by Hau et al., 2010 and Hau, 2011). In December 2000, MSCI announced that it would change all its indexes to adjust the market capitalization by the free-float rate (the proportion of the stocks publicly available), becoming effective in two steps, in November 2001 and May 2002. In fact, the changes in $E_{c t}^{B}$ at those times were indeed much larger (due to the benchmark changes) than during the other months (Online Appendix Figure 2). We regress the changes in mutual fund weights against the changes in the buy-and-hold component and the changes in the exogenous component for the months when MSCI made the change effective. With the exception of the truly active funds, mutual funds responded almost one-to-one to the exogenous changes at the time the indexes were readjusted (Table 3). ${ }^{31}$

From all these exercises we conclude that it is unlikely that our results on the benchmark effect are mainly driven by omitted variables or reverse causality. The evidence is consistent with a causal link from changes in benchmark weights to changes in fund weights.

\section{Benchmarks and capital flows}

To quantify how much of the mutual fund flows is driven by benchmarks, we start from the following identity that captures the relation between benchmark weights and flows:

\footnotetext{
${ }^{31}$ Explicit indexing funds are excluded in these estimations due to the low number of observations.
} 


$$
F_{i c t}=w_{i c t} F_{i t}+\tilde{A}_{i t}\left(w_{i c t}-w_{i c t}^{B H}\right)
$$

where $F_{i c t}$ is the net flow (in dollars) from fund $i$ in country $c$ at time $t . w_{i c t}$ is the portfolio weight the fund decides to have in that country at time $t, \tilde{A}_{i t}=R_{i t} A_{i t-1}$ is the value of the fund's assets at the beginning of time $t$, and $w_{i c t}^{B H}$ is the fund's buy-and-hold weight in that country resulting from movements in total and relative returns. $F_{i t}$ is the net flow (in dollars) to fund $i$ at time $t$, also known as injections or redemptions. ${ }^{32}$

Then, using Equation (1) that links $w_{i c t}$ and $w_{i c t}^{B}$, we decompose Equation (6) into:

$$
F_{i c t}=\alpha w_{i c t}^{B} F_{i t}+\Delta_{i c t}^{B} F_{i t}+\tilde{A}_{i t}\left[\alpha w_{i c t}^{B}-\alpha w_{i c t-1}^{B} \frac{R_{c t}}{R_{i t}}\right]+\tilde{A}_{i t}\left[\Delta_{i c t}^{B}-\Delta_{i c t-1}^{B} \frac{R_{c t}}{R_{i t}}\right],
$$

where $\Delta_{i c t}^{B}=w_{i c t}-\alpha w_{i c t}^{B}$.

The four terms in Equation (7) capture different components of mutual fund flows across countries. The first two terms measure how the manager allocates the injections/redemptions the fund faces. The first one captures how injections/redemptions are distributed according to the benchmark weight, the "benchmark flow," and the second one according to the active weight, the "active flow." The third and fourth terms relate to asset reallocations. The third term indicates how the manager reallocates assets when there is an exogenous change in the benchmark weight, the "benchmark reallocation." The fourth term shows how the manager actively reallocates assets, the "active reallocation." The first and third terms jointly capture the benchmark-related capital flows, while the second and fourth terms are associated with the active decisions of the manager.

A variance decomposition based on Equation (7) shows that benchmarks account for a non-trivial 38.7 percent of the variation of capital flows when considering all funds in the sample (Table 4, Panel A). The benchmark flow explains 16.1 percent and the benchmark reallocation 22.6 percent of mutual fund flows. These percentages vary according to how active a fund is. Benchmark reallocation explains 67.8 percent of mutual fund flows for explicit indexing funds,

\footnotetext{
32 By mutual fund flows or capital flows we mean the flows of the funds we analyze into countries in which they invest. Because we do not have aggregate detailed data for all countries, we cannot determine to what extent these fund flows are reflected in the aggregate balance of payments statistics. However, according to some estimates, the EPFR funds alone account for around 25 percent of total foreign portfolio investments (from all sources) at the country level (Puy, 2013) and there is a significant correlation between the EPFR flows and those obtained from the balance of payments (Fratzscher, 2012; Miao and Pant, 2012).
} 
while this percentage is 12.3 percent for truly active funds. There is also considerable variation across time. When considering months in which MSCI rebalances its indexes, benchmarks explain around 72.7 percent of mutual fund flows, while this percentage drops to 14.3 percent in the other months (Table 4, Panel B and C). Moreover, during the MSCI methodological change in 2001-2002 the percentage explained by the benchmark reallocation increases significantly.

Because the fraction of capital flows explained by benchmarks seems to be much more important when there are large exogenous changes in benchmark weights, we additionally compute the variance decomposition for four different countries that experienced an upgrade or downgrade in our sample, Argentina, Colombia, Israel, and Venezuela (Online Appendix Table 4). For these episodes, the benchmark reallocation explains a much larger fraction of capital flows, ranging from 27.5 percent (in Venezuela) to 62.9 percent (in Israel). This pattern is more accentuated when considering explicit indexing funds. In Israel, the benchmark reallocation term explains 88.7 percent of capital flows of explicit indexing funds, which shows the large importance of benchmark reallocations during large exogenous changes in benchmark weights.

\section{Benchmarks, asset prices, and exchange rates}

While the evidence above on capital flows shows the different channels through which benchmarks can affect mutual fund flows, it does not provide information about the aggregate impact of the benchmark effect. To do so, we would need high-frequency information on capital flows from the balance of payments, which most countries do not report. In this section we measure instead the aggregate effect by showing the reaction of asset prices and exchange rates.

We conduct event study analyses of asset prices and exchange rates around episodes when the benchmark effect is clear to identify, such as, country upgrades and downgrades in both debt and equity markets. For each episode, we identify both the announcement and effective dates. We use a range of 79 well-identified episodes across developed, emerging, and frontier countries (listed in Online Appendix Table 3).

This type of analysis presents at least four methodological advantages to study the effect of benchmarks vis-à-vis the informational effect revealed by the benchmark change itself, when incorporations into an index might anticipate excess returns (Shleifer, 1986; Denis et al., 2003). 
First, because most of these country reclassifications are announced with certainty from 3 to 12 months prior to the effective date, we are able to analyze when (and if) prices react. To the extent that asset prices react at the effective date, not only at the announcement date, it would indicate that not all investors fully anticipate the benchmark change, even when the information about the change is known in advance. ${ }^{33}$

Second, our data allow us to distinguish the positive information the upgrade implies from the mechanical reallocation the benchmark change entails. In particular, when countries are reclassified across categories (developed, emerging, and frontier) their benchmark weight changes significantly, because countries typically receive a weight proportional to their market capitalization. While an upgrade from the emerging to the developed category tends to imply good news, the weight of the country gets reduced because the country is much larger among emerging economies than among developed ones. Given that the pool of assets managed across developed and emerging markets is roughly similar, the benchmark effect related to the reallocation could explain why an upgrade might generate capital outflows and a negative price effect, and a downgrade the opposite movements.

Third, we are able to analyze whether large upgrades and downgrades have effects on countries other than those being upgraded/downgraded. If a country with an important benchmark weight in an index is moved to another index, countries in the original index should experience a considerable positive impact from this change as investors would need to reallocate their investments into the fewer remaining countries. Even when the upgrade/downgrade of a country is informationally relevant for that country, it would not be relevant for third countries sharing the benchmark, which would highlight the importance of the benchmark effect.

The episodes we use can be divided into four types. First, MSCI upgrades/downgrades countries by announcing whether a country is switched and the effective date in which this change will eventually occur. In most of the cases, there is a significant gap between the announcement and the effective dates. For our analysis, we take the announcement and effective date as two separate episodes. For the former, we analyze returns during the day of the

\footnotetext{
${ }^{33}$ This lack of full anticipation is present even in liquid U.S. Treasury security markets (Lou et al., 2013).
} 
announcement, as well as during a window covering up to 30 business days afterwards to analyze the persistence of the event. Because the effective date is known in advance and because our data on explicit and closet indexing funds show that they rebalance their portfolio a few days before the effective date, we use a window starting two business weeks before the effective date and analyze the returns between that point and the subsequent 30 business days. We study the behavior of the MSCI stock market index of the countries that receive the grade change. As the global factor we use the MSCI All Country World Index.

Second, we analyze the contagion effects of the upgrade of Qatar and U.A.E. from frontier to emerging market status in May 2014 on other frontier countries. As the announcement date we use April 1, 2014, when MSCI announced the definitive structure of the new MSCI Frontier Markets Index. We also look at the rebalancing of the iShares MSCI Frontier Markets 100 ETF to pin down the exact date when explicit indexing funds started moving their portfolio to adjust to the large movements experienced in the two upgraded countries. As above, we analyze a window starting two weeks before the effective date, up to the following 30 business days. We use again the MSCI All Country World Index as a global factor. Because of the reallocation within the frontier market index during the effective date, capital outflows were expected in Qatar and U.A.E. (they had already entered into the emerging market funds) and capital inflows were expected in the rest of frontier markets.

Third, similarly to the MSCI benchmark changes, we use 13 different episodes from Barclays, Citigroup, and J.P. Morgan, the three largest debt index producers at the international level. The changes involve the addition of local currency denominated government bonds in the indexes they construct. The total index return for each country is the J.P. Morgan GBI-EM country index, which is a market capitalization based index of the different local currency government bonds. The global factor is the J.P. Morgan GBI, a market-capitalization index of government debt of all the countries. We analyze total returns from these indexes in U.S. dollars. Because all the countries we analyze are in some way upgraded or downgraded from a standalone index, we expect capital flows in the direction of the upgrade or downgrade. 
Fourth, we use upgrades and downgrades between non-investment and investment grade in debt markets, announced by Fitch, Moody's, and S\&P (the main three rating agencies). While these episodes do not necessarily entail movements by the mutual funds that follow the benchmarks used in this paper, several institutional investors have a mandate to invest only in investment grade debt instruments. Therefore, we would expect reallocations and price movements in sovereign debt markets with these events, in particular, a positive effect from an upgrade and a negative one from a downgrade. We consider only the first announcement by any of the big three rating agencies because markets usually expect the other two rating agencies to follow suit. In most of these events, the announcement and effective dates are the same, so we use a window starting the day of the announcement up to 30 business days afterwards. In the three cases for which there is a distinct announcement date, we use both dates. ${ }^{34}$ Because the movements between investment and non-investment grade should affect all the existing government debt of a country, we analyze the broadest possible index, the J.P. Morgan EMBI Country Index. As the global factor, we use the J.P. Morgan EMBI Global Index.

We use three different types of returns: raw returns, excess returns, and abnormal returns. Raw returns are the returns of the stock/debt market index that received the shock. Excess returns are the returns of the country minus those of the global factor. Abnormal returns are the residuals of a regression of the returns of the country relative to the returns of the global factor during the 180 business days prior to the initial event. We compute the cumulative returns starting two days before the initial date and report a mean test of whether these average cumulative returns are different from zero. ${ }^{35}$

We also estimate the same specifications but using exchange rates instead. We exclude countries with hard or soft pegs (as taken from the IMF AREAER) and use as a global factor the average change in exchange rates for all the countries in our sample. We expect an appreciation (depreciation) for episodes when the benchmark change implies capital inflows (outflows). However, the effect on the exchange rates is expected to be lower than that on the specific asset

\footnotetext{
${ }^{34}$ The announcements in all these cases are different from the ones described earlier, because countries are put in a watch list, which does not imply with certainty that an event will happen.

${ }^{35}$ We pool the negative and positive events by normalizing the negative events to be tested as positive ones.
} 
prices because the benchmark change involves only equity or debt. Equity and debt flows might move in different directions (as shown in the next section for the case of Israel's balance of payments) and other factors also affect exchange rates.

The results show that, when considering all the possible events (including the announcement and effective dates), there is a positive and significant reaction of asset returns during the event times that is maintained even for the subsequent 30 business days (Table 5 , Panel A). Raw returns increase by 2.62 percent at their peak. Even excess and abnormal returns show an almost 1.52 and 1.83 percent increase at their peak during the event times, suggesting a significant effect of benchmark changes on asset prices.

When considering only the announcement dates (Table 5, Panel B), there are positive and statistically significant returns across all specifications during the event date and later, suggesting that the effect from benchmark changes is permanent. When considering only the effective date (Table 5, Panel C), there are no effects in the two weeks prior to the effective date. ${ }^{36}$ However, during the week prior to the effective date, the average cumulative returns (of all types) increase significantly: these returns go from 3.5 to 4.3 across the different specifications. Even four weeks after the initial effective date, the effect does not tend to vanish, indicating that there is not a complete reversal of the effect.

We also observe a statistically significant effect in the exchange rates. At the peak, the average exchange rate appreciates/depreciates between 0.5 and 0.61 percent when considering both the announcement and effective dates of an upgrade/downgrade. These effects are present both separately during the announcement and effective dates. Although they keep the sign, these effect become statistically insignificant after two weeks. One possible explanation is that some governments intervene to stabilize the exchange rate. Still, the effects are not negligible given that exchange rates have been hard to predict, capture many factors, and when predictability appears it does so only for some countries and short time periods (Rossi, 2013).

\footnotetext{
${ }^{36}$ Whereas the daily data on passive funds for some episodes suggest that they start doing the reallocations two weeks prior to the effective date, the effects on returns only appear during the week before the event, suggesting that the large reallocations happen during that week.
} 
The distinction between the two types of dates (announcement and effective) allows us to draw some conclusions about the apparent effect of benchmarks on asset prices. First, because most mutual funds move during the effective date and asset prices react then as well, there does not seem to be a complete arbitrage from other investors during the initial announcement. Second, another interesting finding is that returns seem to peak exactly during the effective date, indicating that there might be a price pressure effect and, perhaps, not enough liquidity in the markets to satisfy the shift in demand from the funds following the benchmark. This generates large abnormal returns that afterwards experience a partial reversion. Third, the size of the effects seems to be much larger during the effective date than during the announcement date. This suggests that the mechanical reallocations that take place during the effective date are more important than the changes that occur, due to anticipation, during the announcement date.

\section{Case studies}

In this section, we illustrate with some cases how the benchmark effect can work in practice by focusing on countries that have suffered significant benchmark changes and for which data can be obtained. The section also shows how different variables (mutual fund weights, mutual fund and aggregate capital flows, and prices) change when benchmarks are modified.

We start with the case of Israel, which illustrates well the impact of benchmarks through the different channels. The change in Israel is part of the often-large restructurings that indexproducing companies announce about the calculation of their indexes. The most important changes entail upgrades/downgrades of countries between the categories developed, emerging, and frontier markets and changes related to the index construction methodology.

In June 2009, MSCI announced its decision to upgrade Israel from emerging to developed market status. In May 2010, the benchmark weight of Israel in the MSCI Emerging Markets Index turned zero and its weight in the MSCI World Index became positive. Figure 2 shows the behavior of the average weight of Israel among the explicit indexing and truly active funds that declare to follow the MSCI Emerging Markets Index and the MSCI World Index. Explicit indexing funds track the benchmark very closely. At the time the upgrade became 
effective, the funds that tightly follow the MSCI Emerging Markets Index instantly dropped Israel's weight to zero, while those following the MSCI World Index incorporated Israel to their portfolios. However, when MSCI announced the upgrade decision, these funds did not significantly change their allocation in Israel; instead, they waited until the actual upgrade materialized. Truly active funds did not react so mechanically to the upgrade, but they still gradually adjusted their portfolio in a manner that is consistent with movements in the benchmark weights.

This example shows how there is a very tight connection between benchmarks and passive funds and a looser connection between benchmarks and active funds. It also shows that the reclassification of countries across benchmarks can trigger asset liquidation to reduce the country exposure, not driven by price effects. While the Israel example involved large reallocations and a complete removal and incorporation into two different indexes, there are many more frequent but smaller changes in the indexes.

To understand the total effect on country flows, it is important to consider that, at that time, Israel's weight in the MSCI Emerging Markets Index was 3.17 percent and in the MSCI World Index 0.37 percent, and the assets in the funds following these two indexes were not very different. Thus, as expected, emerging market funds withdrew 2 billion U.S. dollars from Israel while developed market funds injected 160 million.

This effect at the mutual fund level is in fact similar in size with the movements registered in Israel's balance of payments (Figure 3, Panel A). Moreover, this outflow differs from the inflows in other quarters and in debt flows in the same quarter. In particular, during the previous three years to the effective date, there were significant inflows to equity securities, while during the second quarter of 2010 (the effective date) there were almost 2.3 billion U.S. dollars outflows in equities compared to 2 billion U.S. dollars inflows in debt. The magnitude and direction of the equity flows are consistent with mutual funds reallocating their portfolio and inconsistent with the overall positive inflows that Israel was receiving around the upgrade event. The equity capital flows move in a different direction than the upgrade would suggest if the event just contained good news for Israel, and thus point to the importance of the benchmark effect. 
In terms of prices, the Israeli stocks in the MSCI index fell almost 4 percent in the week of the announcement and underperformed the MSCI All Country World Index, even when the news was an upgrade (Figure 3, Panel B). Moreover, the week prior to the effective date (when index funds rebalanced their portfolio) there was a 4.2 percent drop in the MSCI Israel Index. Still a month after the effective date, there was a considerable gap between the MSCI Israel Index and the MSCI All Country World Index (Figure 3, Panel C).

Another interesting case is that of Colombia's debt market. On March 19, 2014, J.P. Morgan announced that it would add five Colombian Treasury (TES) bonds to its Global Bond Index-Emerging Markets and Global Bond Index-Emerging Markets Diversified. Colombia's benchmark weight would increase from 3.2 to 8 percent in the latter and from 1.8 to 5.6 percent in the former. Data from national sources show that when the benchmark changed the share of Colombian TES bonds held by foreigners increased by a factor of around 2.33 (Figure 4, Panel A). This was driven by an increase in the total purchases of these securities by foreigners, showing a marked difference with previous periods. This episode also shows that the benchmark effect is relevant not only during upgrades or downgrades (extensive margin), but also during significant revisions of the benchmark weight within an index (intensive margin). Three weeks after the announcement, the Colombian local currency bond Index was up 5 percent compared to the J.P. Morgan GBI (Figure 4, Panel B), showing a large benchmark effect.

The upgrade of Qatar and U.A.E. from frontier to emerging market status in May 2014 shows that the benchmark effect can also generate significant shocks and reallocations across countries, bringing home changes to the rest of the countries sharing the same benchmark and producing contagion-like effects. This change triggered a large positive effect to other countries that shared the portfolio with these countries. This occurred because Qatar and U.A.E. accounted for around 40 percent of the MSCI Frontier Markets Index, and the other countries in the index were relatively small. Figure 5, Panel A depicts the cumulative reallocation of capital flows by frontier markets passive funds during these upgrades. While there is no reaction during the initial announcement date, during the three effective dates in our sample (the adjustment 
took place gradually) these funds reallocated their holdings out of the upgraded countries and into the other frontier countries.

Because Qatar and U.A.E. comprised around 40 percent of the MSCI Frontier Markets Index, the rest of the frontier markets were expected to have their benchmark weight increased considerably as frontier market funds reallocated away from Qatar and U.A.E. ${ }^{37}$ The country comparison shows that, when the upgrade was announced, there was an increase in prices of the stocks of the other frontier countries in the MSCI index (Figure 5, Panel B). Coinciding with the movements in capital flows described in Figure 5 around the effective date, the asset prices of these countries increased when compared to the MSCI All Country World (Figure 5, Panel C). These jumps occurred during the days when passive funds rebalanced their portfolios.

\section{Conclusions}

This paper shows how benchmarks affect asset allocations, capital flows, asset prices, and exchange rates across countries using a novel dataset of well-known benchmark indexes and mutual funds from around the world investing in equities and bonds. We find that benchmarks have important effects on these variables not only because funds explicitly declare a benchmark to compare their performance, but also because both passive and active funds tend to follow their benchmark asset allocation rather closely. The effects of benchmarks on mutual fund allocations are significant even after controlling for industry effects, country-time effects, macroeconomic fundamentals, and after addressing potential omitted variables and reverse causality problems. The decisions about allocations impact non-trivially capital flows and the upgrades and downgrades of countries are associated with significant price changes.

Although the results do not mean that benchmarks explain all the movements in capital flows, their impact can be particularly important at some points in time, for example, when benchmarks can coordinate managers across institutions whose actions are felt at the systemic

\footnotetext{
${ }^{37}$ Given the size of the expected reallocation in the MSCI Frontier Markets Index, MSCI considered not removing Qatar and U.A.E. from this index (even when they would still be moved to the emerging market category). In the end, it decided to move forward with the removal, but did it gradually to ameliorate the disruption in the markets (MSCI Barra, 2014).
} 
level. ${ }^{38}$ Benchmark movements could explain not only some of the findings documented in the literature, but also counterintuitive and unexpected movements in cross-country investments and asset prices. For example, advanced emerging countries tend to have larger weights in emerging market indexes than in developed market ones, which can help explain why countries might face capital outflows (inflows) when they are upgraded (downgraded). Moreover, countries sharing the benchmark are faced with capital inflows and asset price increases when a large country is removed from the index, regardless of their fundamentals. This kind of contagion does not involve leverage and is different from other types of contagion described in the literature (Calvo and Mendoza, 2000; Kodres and Pritsker, 2002; Manconi et al., 2012; Hau and Lai, 2013).

By impacting international capital flows, benchmark changes at the country level are also associated with aggregate price effects. In particular, stock and debt price indexes and exchange rates revalue or devalue depending on whether the benchmark changes imply capital inflows or outflows. These effects are observed not only during the announcement of the event but also during the date in which the benchmark changes become effective. These results are consistent with the importance of trading by investors following benchmarks, and take place beyond any information content that benchmark changes might entail. They also suggest possible limits to arbitrage in these markets when those announcements are made.

Although this paper presents several new findings, the research on the effects of benchmarks is just at the early stages. The evidence suggests that funds worldwide are becoming less active (Cremers et al., 2013; The Economist, 2014b; Financial Times, 2015) and the number of benchmarks are increasing rapidly. Therefore, the types of mechanisms documented here are expected to grow over time and the literature might start incorporating them.

One issue that remains to be understood is whether the use of benchmarks can provide an explanation for the momentum and feedback loop theories (Barberis et al., 1998; Daniel et al.,

\footnotetext{
${ }^{38}$ In particular, through their effect on individual portfolios, benchmarks could lead mutual funds to move in tandem in given countries. This is important because individual funds tend to be relatively small compared to the size of capital flows to a country, but together they can be quantitatively large. While there is a large literature showing that mutual funds might imitate their peers and display herding-type behavior (Scharfstein and Stein, 1990; Froot et al., 1993; Hirshleifer et al., 1994; Hong et al., 2005), only a handful of cases document coordination at the empirical level (Chen et al., 2010; Hertzberg et al., 2011). This paper provides evidence consistent with another coordinating mechanism.
} 
1998; Shiller, 2000; Gervais and Odean, 2001; Vayanos and Wooley, 2013). A shock to a country's return could lead to a higher benchmark weight, a larger mutual fund allocation, and larger capital flows if funds are receiving inflows and capital is slow moving, perpetuating these loops. Benchmarks might also explain why international mutual funds can behave pro-cyclically, herd, and affect financial markets, increasing volatility and disconnecting asset prices from macroeconomic fundamentals (Kaminsky et al., 2004; Gelos and Wei, 2005; Khorana et al., 2005; Broner et al., 2006; Shiller, 2008; Hellwig, 2009; Mishkin, 2011; Maug and Naik, 2011; Forbes et al., 2012; Fratzscher, 2012; Jotikasthira et al., 2012; Levy Yeyati and Williams, 2012; Raddatz and Schmukler, 2012; Gelos, 2013; Stein, 2013; IMF, 2014; Ahmed et al., 2015; Goldstein et al., 2015; Shek et al., 2015).

Another issue pending study is the general equilibrium effects of benchmarks when there are heterogeneous investors. Our results show quantity and price responses even to fully anticipated events. Given that some funds try to replicate their benchmark index almost mechanically, do other funds or sophisticated investors anticipate or compensate for their reaction? Or do they also follow these benchmarks? And what are the effects of benchmarks on small and large firms' capital market financing and real activity? 


\section{References}

Ahmed, S., Curcuru, S., Warnock, F., Zlate, A., 2015. The Two Components of International Capital Flows. Federal Reserve Board, mimeo.

Antràs, P., Caballero, R., 2009. Trade and Capital Flows: A Financial Frictions Perspective. Journal of Political Economy, 117 (4), 701-744.

Barberis, N., Shleifer, A., Vishny, R., 1998. A Model of Investor Sentiment. Journal of Financial Economics, 49 (3), 307-343.

Barberis, N., Shleifer, A., Wurgler, J., 2005. Comovement. Journal of Financial Economics, 75 (2), 283-317.

Bartram, S., Griffin, J., Lim, T.H., Ng, D., 2015. How Important Are Foreign Ownership Linkages for International Stock Returns? Review of Financial Studies, 28 (11), 3036-3072.

Goldstein, I., Jiang, H., Ng, D., 2015. International Flows and Fragility in Corporate Bond Funds. Wharton School, mimeo.

Basak, S., Pavlova, A., 2012. Asset Prices and Institutional Investors. American Economic Review, 103 (5), 1728-1758.

BIS, 2014. International Banking and Financial Market Developments. BIS Quarterly Review.

Bloomberg, 2014. MSCI Upgrade Unwanted as Emerging Beats Developed. June 3.

Brennan, M., 1993. Agency and Asset Pricing. UCLA Working Paper.

Broner, F., Gelos, G., Reinhart, C., 2006. When in Peril, Retrench: Testing the Portfolio Channel of Contagion. Journal of International Economics, 69 (1), 203-230.

Busse, J., Goyal, A., Wahal, S., 2014. Investing in a Global World. Review of Finance, 18 (2), 561 590.

Business Week, 2010. Israel Gets an Upgrade, and Investors Depart. September 9th.

Calvo, G., Mendoza, E., 2000. Rational Contagion and the Globalization of Securities Markets. Journal of International Economics, 51 (1), 79-113.

Chakravorti, S., Lall, S., 2004. Managerial Incentives and Financial Contagion, IMF Working Paper 4/199.

Chang, Y.-C., Hong, H., Liskovich, I., 2015. Regression Discontinuity and the Price Effects of Stock Market Indexing. Review of Financial Studies, 28 (1), 212-246.

Chen, H., Noronha, G., Singal, V., 2004. The Price Response to S\&P 500 Index Additions and Deletions: Evidence of Asymmetry and a New Explanation. Journal of Finance, 59 (4), 19011929.

Chen, Q., Goldstein, I., Jiang, W., 2010. Payoff Complementarities and Financial FragilityEvidence from Mutual Fund Outflows. Journal of Financial Economics, 97 (2), 239-262.

Claessens, S., Yafeh, Y., 2012. Comovement of Newly Added Stocks with National Market Indices: Evidence from Around the World. Review of Finance, 17, 203-227.

Cremers, M., Ferreira, M., Matos, P., Starks, L., 2016. Indexing and Active Fund Management: International Evidence. Journal of Financial Economics, 120, 539-560.

Cremers, M., Petajisto, A., 2009. How Active Is Your Fund Manager? A New Measure that Predicts Performance. Review of Financial Studies, 22 (9), 3329-3365.

Daniel, K., Hirshleifer, D., Subrahmanyam, A., 1998. Investor Psychology and Security Market Under - and Over- Reactions. Journal of Finance, 53 (5), 1839-1886.

Denis, D., McConnell, J., Ovtchinnikov, A., Yu, Y., 2003. S\&P 500 Index Additions and Earnings Expectations. Journal of Finance, 58 (5), 1821-1840.

Igan, D., Pinheiro, M., 2015. Delegated Portfolio Management, Benchmarking, and the Effects on Financial Markets, IMF Working Paper 15/198.

Di Giovanni, J., 2005. What Drives Capital Flows? The Case of Cross-Border M\&A Activity and Financial Deepening. Journal of International Economics, 65 (1), 127-149.

Didier, T., Rigobon, R., Schmukler, S., 2013. Unexploited Gains from International Diversification: Patterns of Portfolio Holdings around the World. Review of Economics and Statistics, 95 (5), 1562-1583.

Disyatat, P., Gelos, G., 2001. The Asset Allocation of Emerging Market Mutual Funds, IMF Working Paper 01/111.

Driscoll, J., Kraay, A., 1998. Consistent Covariance Matrix Estimation with Spatially Dependent Panel Data. Review of Economics and Statistics, 80, 549-560. 
Faias, J., Ferreira, M., Matos, P., Santa-Clara, P., 2012. Does Institutional Ownership Matter for International Stock Return Comovement? Darden School of Business, mimeo.

Financial Times c, 2013a. Greece Really Is a Submerging Market. June 12.

Financial Times a, 2013b. U.A.E. and Qatar Gain Upgrade to EM Status. June 12.

Financial Times b, 2013c. South Korea: MSCI Upgrade Time? June 20.

Financial Times, 2015. Emerging Market Investors Dominated by Indices. August 4.

Forbes, K., Fratzscher, M., Kostka, T., Straub, R., 2012, Bubble Thy Neighbor: Portfolio Effects and Externalities from Capital Controls. NBER Working Paper No. 18052.

Fratzscher, M., 2012. Capital Flows, Push versus Pull Factors and the Global Financial Crisis. Journal of International Economics, 88 (2), 341-356.

Froot, K., Scharfstein, D., Stein, J., 1993. Risk Management: Coordinating Corporate Investment and Financing Policies. Journal of Finance, 48 (5), 1629-1658.

Gelos, G., 2013. International Mutual Funds, Capital Flow Volatility, and Contagion-A Survey. In The Evidence and Impact of Financial Globalization. Edited by G. Caprio, T. Beck, S. Claessens, and S. Schmukler. Elsevier, 131-143.

Gelos, G., Wei, S.-J., 2005. Transparency and International Portfolio Holdings. Journal of Finance, 60 (6), 2987-3020.

Gervais, S., Odean, T., 2001. Learning to be Overconfident. Review of Financial Studies, 14 (1), 1 27.

Greenwood, R., 2005. Short- and Long-Term Demand Curves for Stocks: Theory and Evidence on the Dynamics of Arbitrage. Journal of Financial Economics, 75 (3), 607-649.

Gourinchas, P., Rey, H., 2014. External Adjustment, Global Imbalances and Valuation Effects. In Handbook of International Economics, Volume 4. Edited by G. Gopinath, H. Helpman, and K. Rogoff. Elsevier, 585-645.

Harris, L., Gurel, E., 1986. Price and Volume Effects Associated with changes in the S\&P 500 List: New Evidence for the Existence of Price Pressures. Journal of Finance, 41 (4), 815-829.

Hau, H., 2011. Global versus Local Asset Pricing: A New Test of Market Integration. Revien of Financial Studies, 24 (12), 3891-3940.

Hau, H., Lai, S., 2013. The Role of Equity Funds in the Financial Crisis Propagation. CEPR Discussion Papers 8819.

Hau, H., Massa, M., Peress, J., 2010. Do Demand Curves for Currency Slope Down? Evidence from the MSCI Global Index Change. Review of Financial Studies, 23 (4), 1681-1717.

Hellwig, M., 2009. Systemic Risk in the Financial Sector: An Analysis of the Subprime-Mortgage Financial Crisis. De Economist, 157 (2), 129-207.

Hertzberg, A., Liberti, J.M., Paravisini, D., 2011. Public Information and Coordination: Evidence from a Credit Registry Expansion. Journal of Finance, 66 (2), 379-412.

Hirshleifer, D., Subrahmanyam, A., Titman, S., 1994. Security Analysis and Trading Patterns When Some Investors Receive Information before Others. Journal of Finance, 49 (5), 1665-98.

Hong, H., Kubik, J., Stein, J., 2005. The Neighbors' Portfolio: Word of Mouth Effects in the Holdings and Trades of Money Managers. Journal of Finance, 60 (6), 2801-2824.

IMF, 2014. Global Financial Stability Report. International Monetary Fund.

Jiang, H., Verbeek, M., Wang, Y., 2014. Information Content when Mutual Funds Deviate from Benchmarks. Management Science, 60 (8), 2038-2053.

Jotikasthira, C., Lundblad, C., Ramadorai, T., 2012. Asset Fire Sales and Purchases and the International Transmission of Financial Shocks. Journal of Finance, 67 (6), 2015-2050.

Kaminsky, G., Lyons, R., Schmukler, S., 2004. Managers, Investors, and Crises: Mutual Fund Strategies in Emerging Markets. Journal of International Economics, 64 (1), 113-134.

Khorana, A., Servaes, H., Tufano, P., 2005. Explaining the Size of the Mutual Fund Industry around the World. Journal of Financial Economics, 78 (1), 145-185.

Kraay, A., Norman, L., Servén, L., Ventura, J., 2005. Country Portfolios. Journal of the European Economic Association, 3 (4), 914-945.

Kodres, L., Pritsker, M., 2002. A Rational Expectations Model of Financial Contagion. Journal of Finance, 57 (2), 769-799.

Lane, P, Milesi-Ferretti, G. M., 2007. The External Wealth of Nations Mark II: Revised and Extended Estimates of Foreign Assets and Liabilities, 1970-2004. Journal of International Economics, 73 (2), 223-250. 
Lehmann, B., Modest, D., 1987. Mutual Fund Performance Evaluation: A Comparison of Benchmarks and Benchmark Comparison. Journal of Finance, 42 (2), 233-265.

Lou, D., Yan, H., Zhang, J., 2013. Anticipated and Repeated Shocks in Liquid Markets. Review of Financial Studies, 26 (8), 1890-1912.

Levy Yeyati, E., Williams, T., 2012. Emerging Economies in the 2000s: Real Decoupling and Financial Recoupling. Journal of International Money and Finance, 31 (8), 2102-2126.

Manconi, A., Massa, M., Yasuda, A., 2012. The Role of Institutional Investors in Propagating the Financial Crisis of 2007-2008. Journal of Financial Economics, 104 (3), 491-518.

Martin, A., Taddei, F., 2013. International Capital Flows and Credit Market Imperfections: A Tale of Two Frictions. Journal of International Economics, 89 (2), 441-452.

Maug, E., Naik, N., 2011. Herding and Delegated Portfolio Management: The Impact of Relative Performance Evaluation on Asset Allocation. Quarterly Journal of Finance, 1 (2), 265-292.

Miao, Y., Pant, M., 2012. Coincident Indicators of Capital Flows. IMF Working Paper 12/55.

Mishkin, F. S., 2011. Over the Cliff: From the Subprime to the Global Financial Crisis. Journal of Economic Perspectives, 25 (1), 49-70.

MSCI Barra, 2014. MSCI to Consult on Potential Changes to the Methodology for the MSCI Frontier Markets 100 Index.

Puy, D., 2013. Institutional Investors Flows and the Geography of Contagion. European University Institute Working Paper 2013/06.

Raddatz, C., Schmukler, S., 2012. On the International Transmission of Shocks: Micro-Evidence from Mutual Fund Portfolios. Journal of International Economics, 88 (2), 357-374.

Reinhardt, D., Ricci, L., Tressel, T., 2013. International Capital Flows and Development: Financial Openness Matters. Journal of International Economics, 91 (2), 235-251.

Roll, R., 1992. A Mean-Variance Analysis of Tracking Error. Journal of Portfolio Management, 18 (4), 13-22.

Rossi, B., 2013. Exchange Rate Predictability. Journal of Economic Literature, 51(4), 1063-1119.

Scharfstein, D., Stein, J., 1990. Herd Behavior and Investment. American Economic Review, 80 (3), 465-479.

Sensoy, B., 2009. Performance Evaluation and Self-Designated Benchmarks Indexes in the Mutual Fund Industry. Journal of Financial Economics, 92 (9), 25-39.

Sharpe, W., 1992. Asset Allocation: Management Style and Performance Measurement. Journal of Portfolio Management, 18 (2), 7-19.

Shek, J., Shim, I., Shin, H.S., 2015. Investor Redemptions and Fund Manager Sales of Emerging Market Bonds: How Are They Related? BIS Working Paper 509.

Shiller, R., 2000. Irrational Exuberance. Princeton University Press. Princeton, NJ.

Shiller, R., 2008. The Subprime Solution: How Today's Global Financial Crisis Happened, and What to Do about It. Princeton University Press.

Shleifer, A., 1986. Do Demand Curves for Stocks Slope Down? Journal of Finance, 41 (3), 579-590.

Stein, J., 2013. Overheating in Credit Markets: Origins, Measurements, and Policy Responses. Speech at the Federal Reserve Bank of St. Louis, February 7.

The Economist, 2012. Nigerian Debt Gets the 'Emerging Market' Seal of Approval. October 27. The Economist, 2014a. Wedge beyond the Edge. April 5.

The Economist, 2014b. Will Invest for Food. May 3.

Vayanos, D., Woolley, P., 2011. Fund Flows and Asset Prices: A Baseline Model. FMG Discussion Paper DP667.

Vayanos, D., Woolley, P., 2013. An Institutional Theory of Momentum and Reversal. Review of Financial Studies, 26 (5), 1087-1145.

Vayanos, D., Woolley, P., 2016. Curse of the Benchmarks. FMG Discussion Paper DP747.

Wermers, R., 2000. Mutual Fund Performance: An Empirical Decomposition into Stock-Picking Talent, Style, Transaction Costs, and Expenses. Journal of Finance, 55 (4), 1655-1695.

Wurgler, J., 2011. On the Economic Consequences of Index-Linked Investing. In Challenges to Business in the Twenty-First Century. Edited by G. Rosenfeld, J. Lorsch, and R. Khurana. American Academy of Arts and Sciences, 20-34. 
Figure 1

Deviations in Mutual Fund and Benchmark Weights

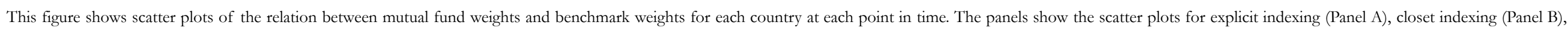

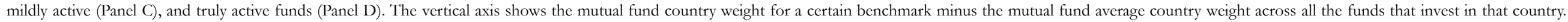

The horizontal axis shows the benchmark weight of a country in a certain benchmark minus the average benchmark weight for the same country across all the benchmarks where the country is included.

\section{A. Explicit Indexing}

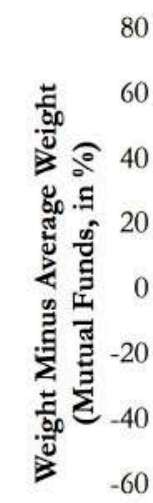

$-80$

$-80$ (1)

0 $-40$

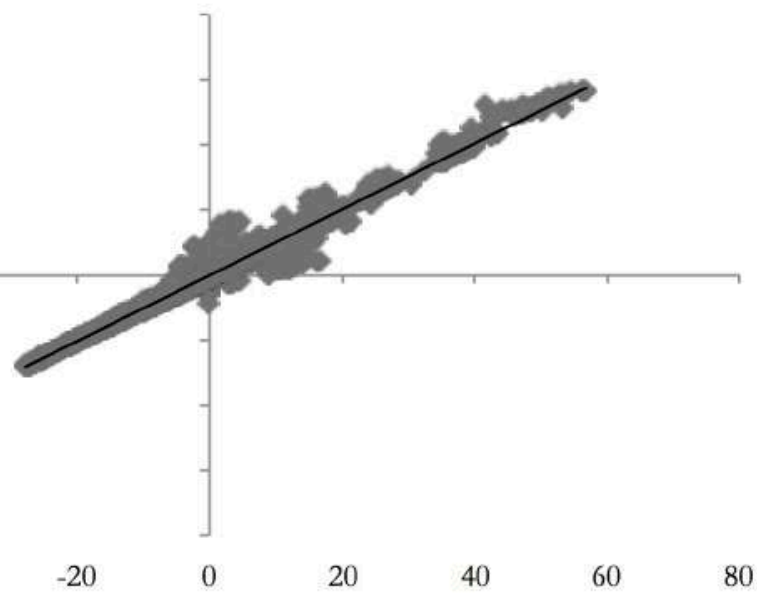

C. Mildly Active

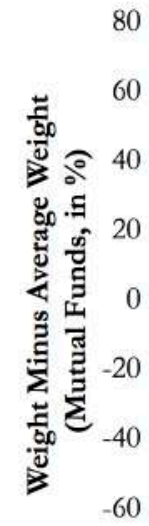

$-80$<smiles>CCC</smiles>

$-80$
(2)

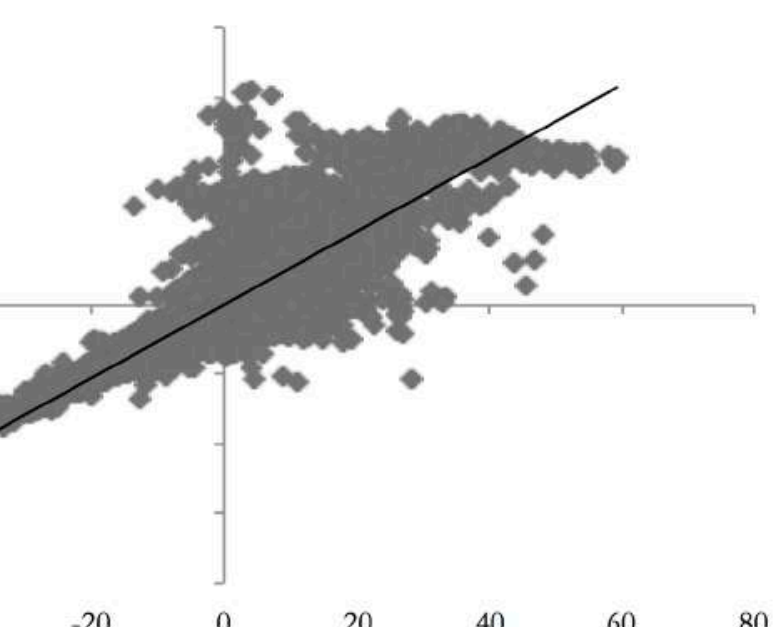

Weight Minus Average Weight (Benchmarks, in \%)
B. Closet Indexing

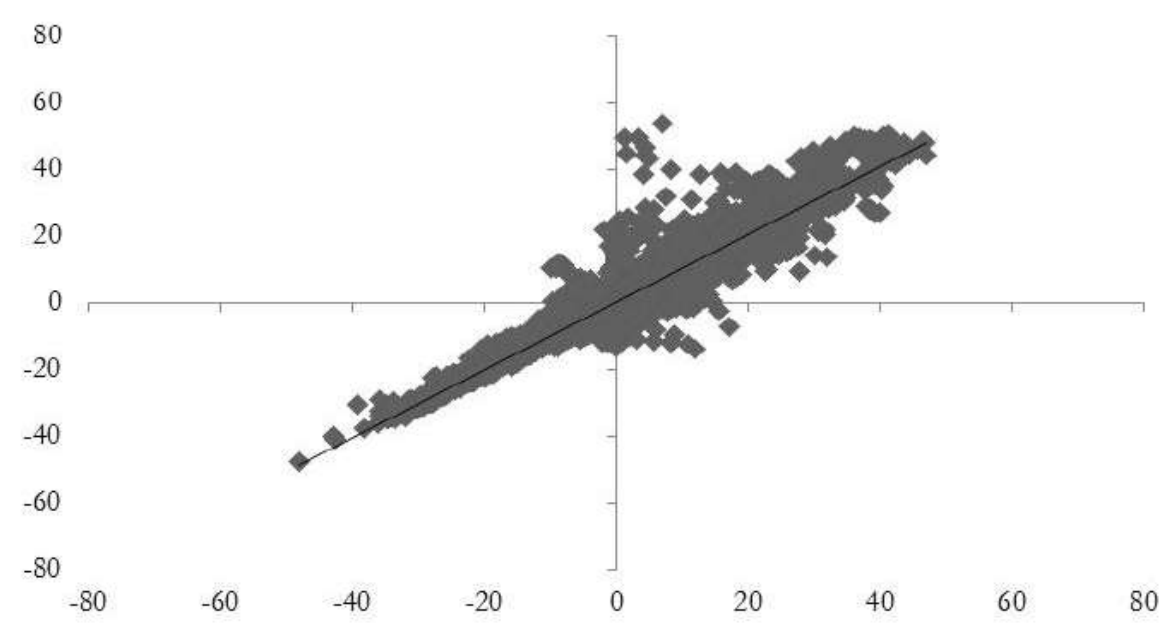

D. Truly Active

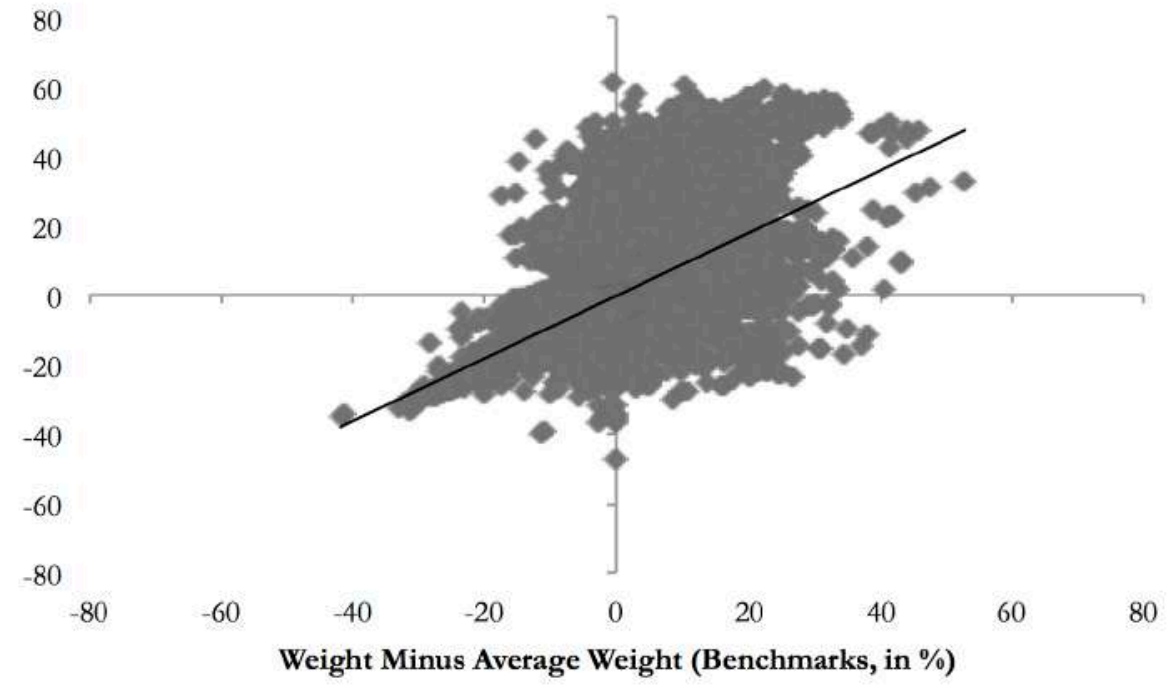


Figure 2

The Upgrade of Israel from Emerging to Developed Market

This figure shows the mean mutual fund and the benchmark weight around the upgrade of Israel from emerging to developed market in the MSCI indexes in May 2010. The mean weight in Israel is the weighted (by TNAs) average across funds for each type of fund. The left panels show the funds following the MSCI Emerging Markets index. The right panels show the funds following the MSCI World index. In each case we include the correspondent benchmark weight (MSCI Emerging Markets or MSCI World). The first grey bar indicates the month of the announcement and the second grey bar indicates the month the upgrade took place.

\section{A. Global Emerging Funds and MSCI Emerging Markets Index}

Explicit Indexing

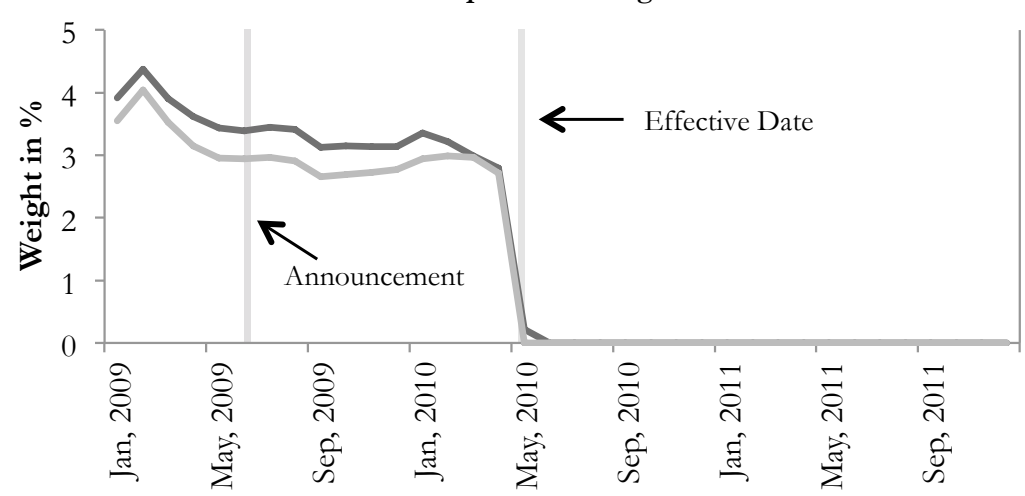

C. Global Emerging Funds and MSCI Emerging Markets Index

Truly Active

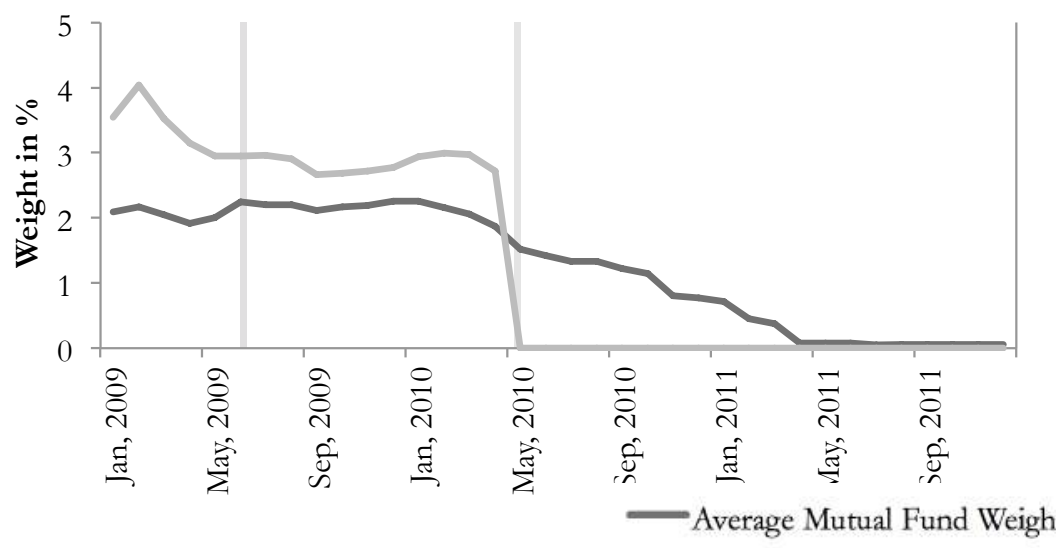

\section{B. Global Funds and MSCI World Index}

Explicit Indexing

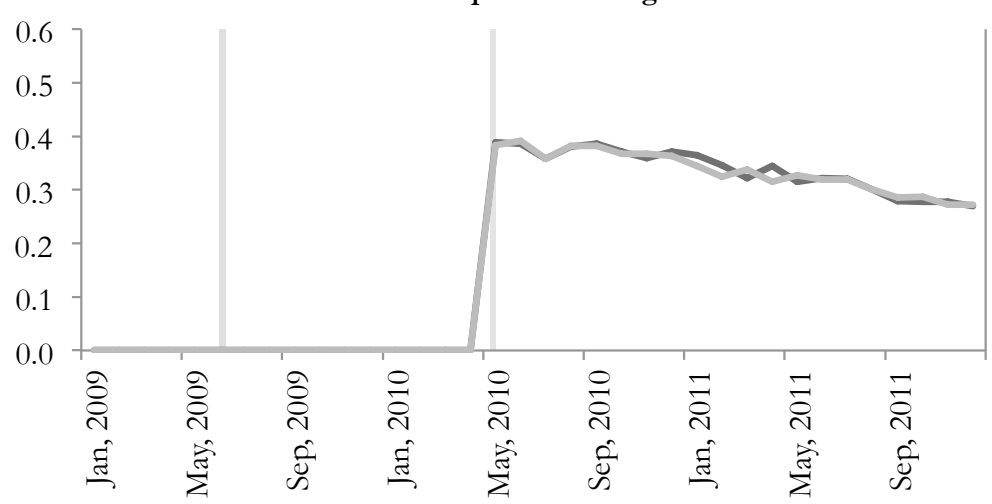

D. Global Funds and MSCI World Index

Truly Active

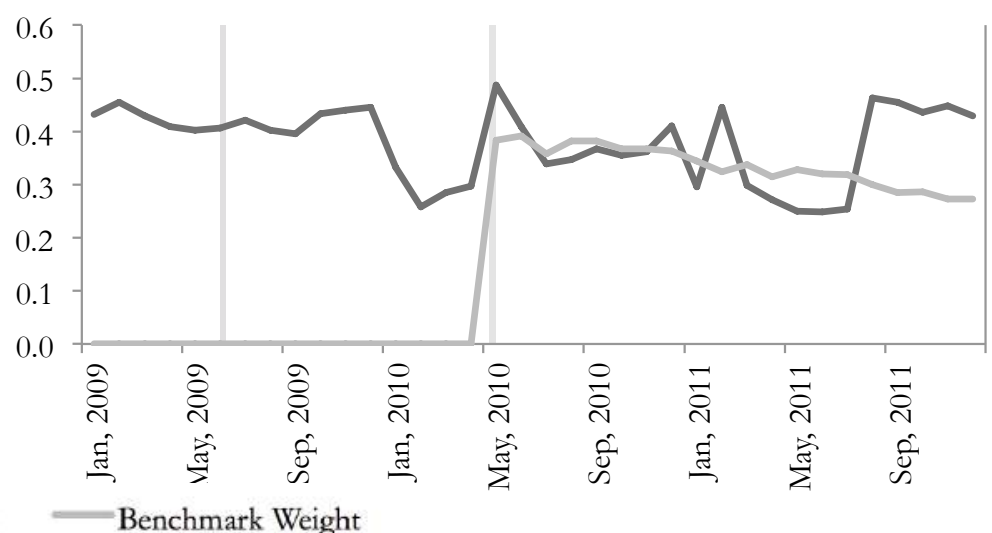


Figure 3

Benchmark Effect: Israel MSCI Upgrade

This figure shows the evolution of aggregate variables around Israel's upgrade. Panel A shows data for portfolio equity liability flows and portfolio debt liability flows for Israel quarterly between 2007 and 2011. Panel B shows the prices around the announcement date and Panel $\mathrm{C}$ around the effective date. Index returns is the Israel MSCI Country Index.

A. Israel Balance of Payments

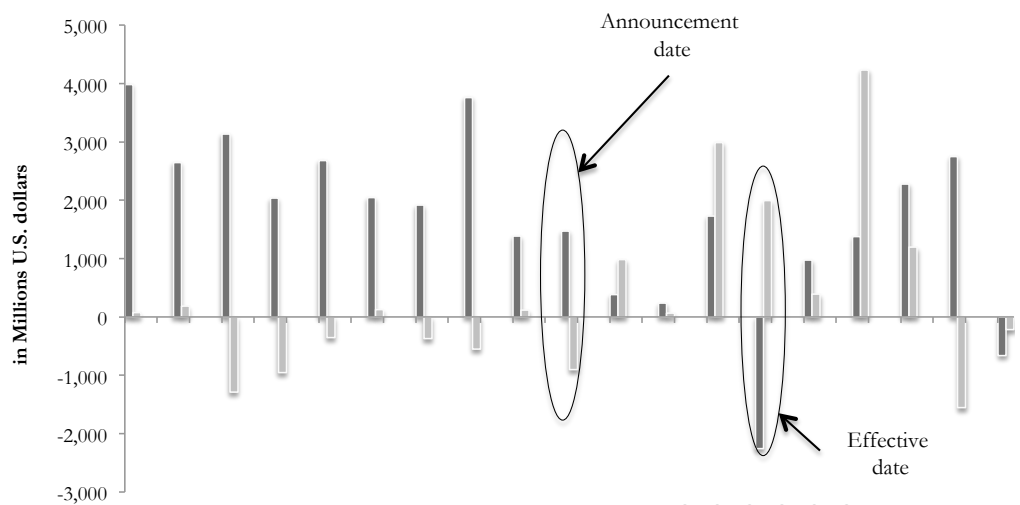

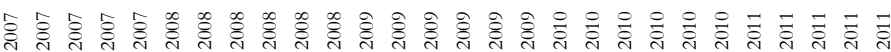

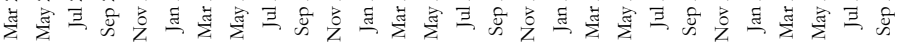

- Portfolio Equity Liability Flows = Portfolio Debt Liability Flows

B. Announcement Date

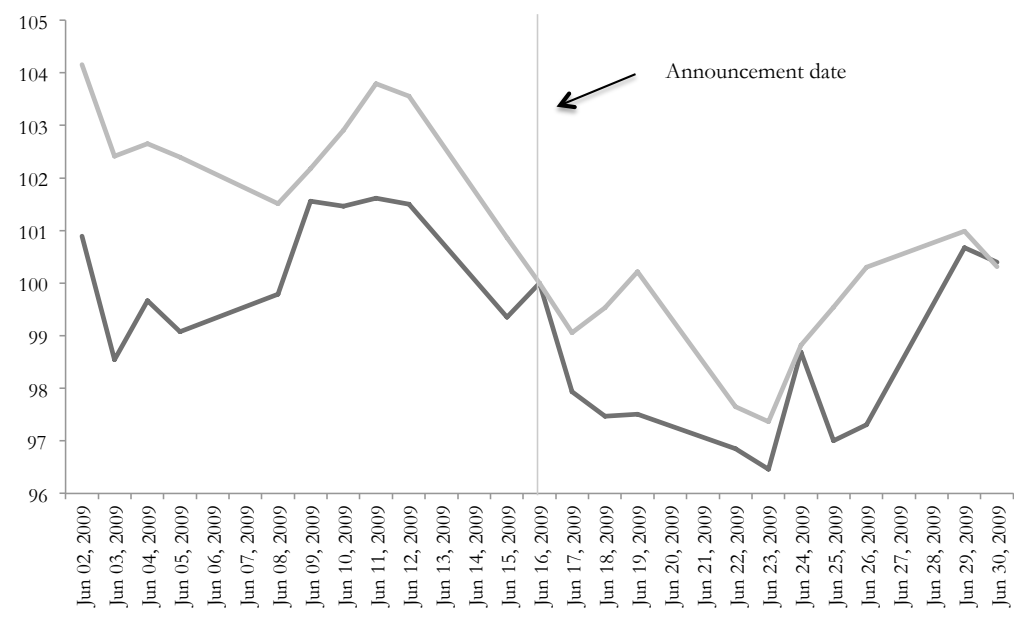

C. Effective Date

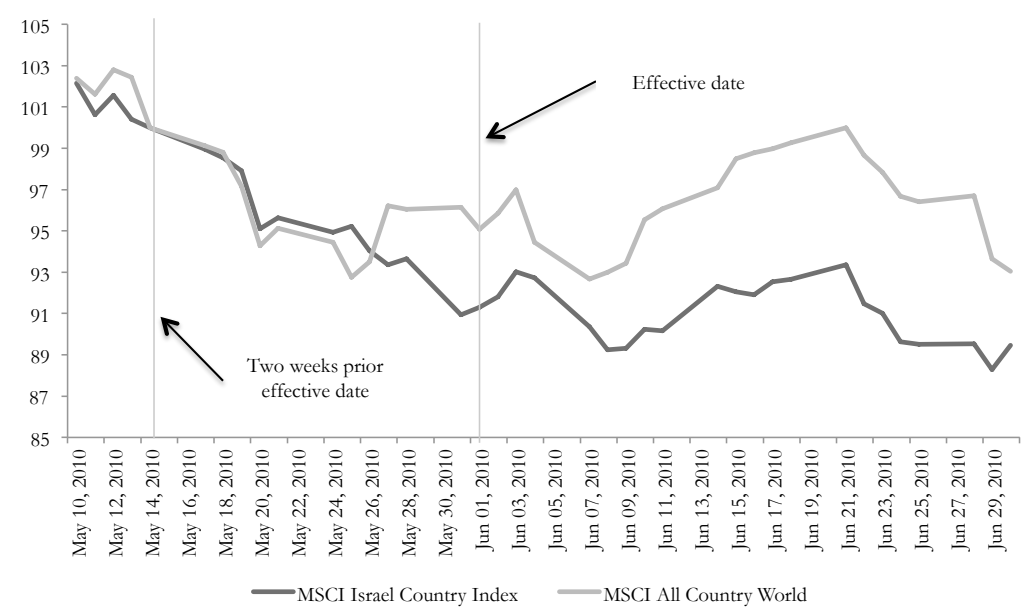


Figure 4

Benchmark Effect: Colombia Sovereign Debt Market

This figure displays the reaction of Colombia's sovereign debt market to a change in benchmarks from J.P. Morgan. Panel A presents the percentage and purchases of TES bond holdings belonging to foreigners in Colombia after J.P. Morgan's announcement about Colombia's increase in the local debt benchmark weight. Panel B shows the debt market for Colombia during the J.P. Morgan increase in weight for Colombia in its local currency denominated sovereign debt index. Indexes are the total return index (in local currency).

\section{A. Participation of Foreigners in TES bonds in Colombia}

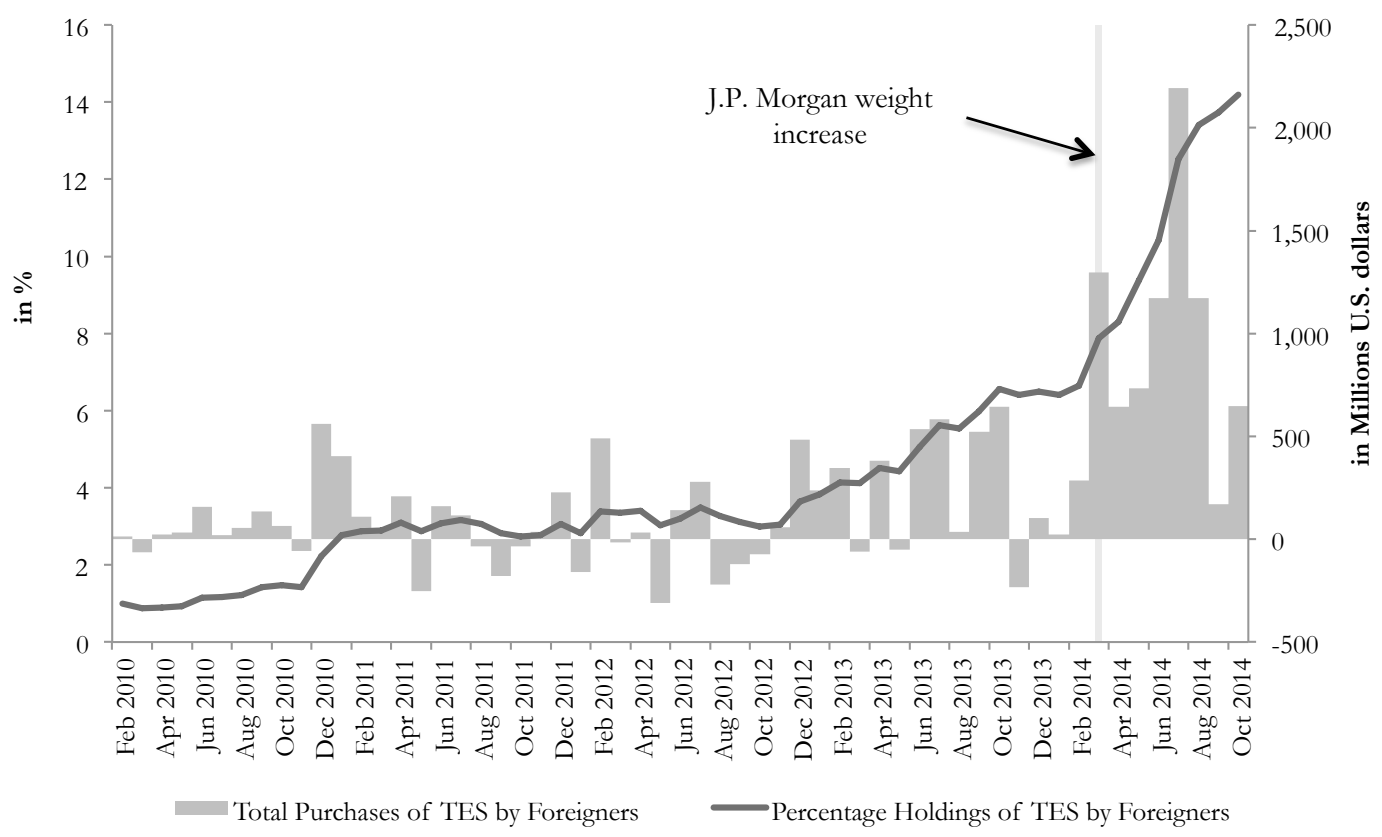

\section{B. Sovereign Debt Prices}

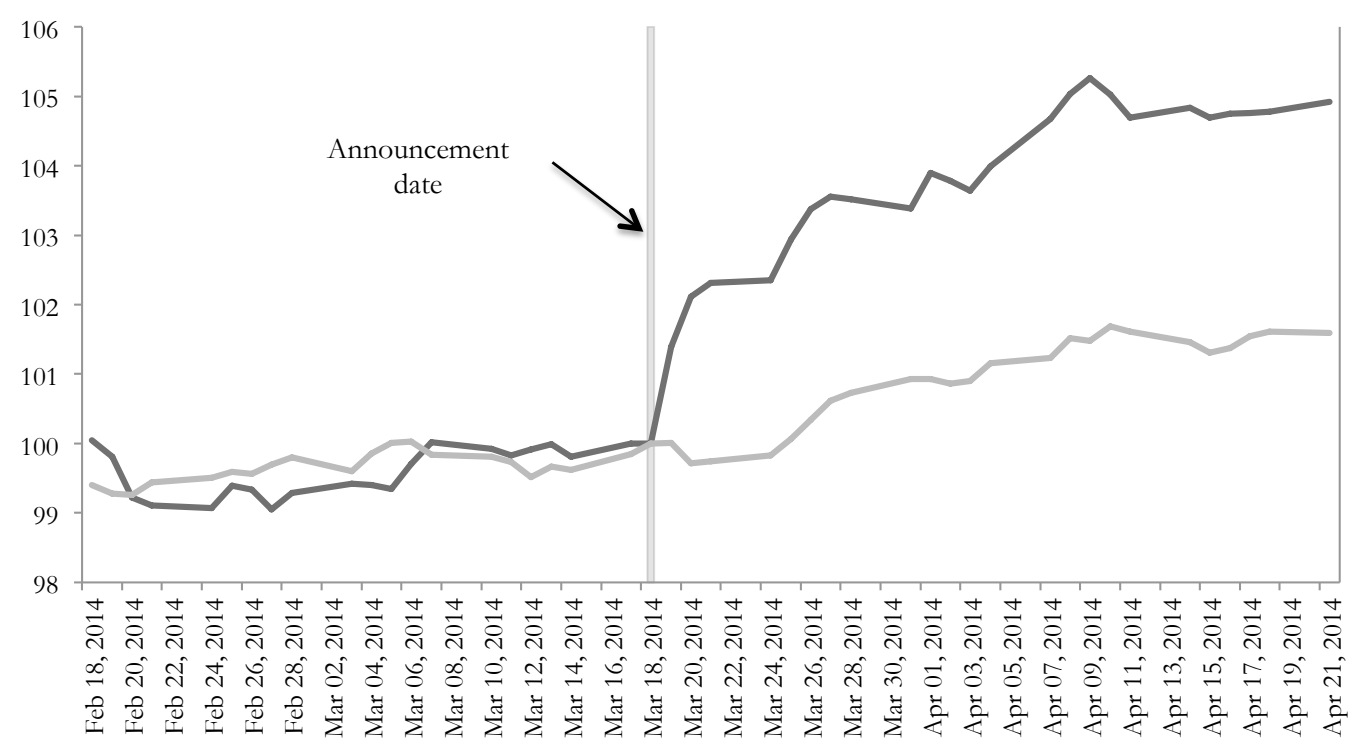


Figure 5

Contagion in Frontier Markets

This figure shows the impact on other frontier countries of the MSCI upgrade of Qatar and United Arab Emirates. Panel A depicts the the total cumulative flows (starting in March 2014) due to reallocation in millions U.S. dollars. The figure is divided into all frontier countries after the upgrade and Qatar plus United Arab Emirates. Panels B and C present the announcement date for the stocks included in the frontier market indexes and a global factor. Panel B presents the effective date of the first rebalancing. Panel C shows the evolution of price for the same two groups for the effective date.

A. Cumulative Flows from Frontier Passive Funds

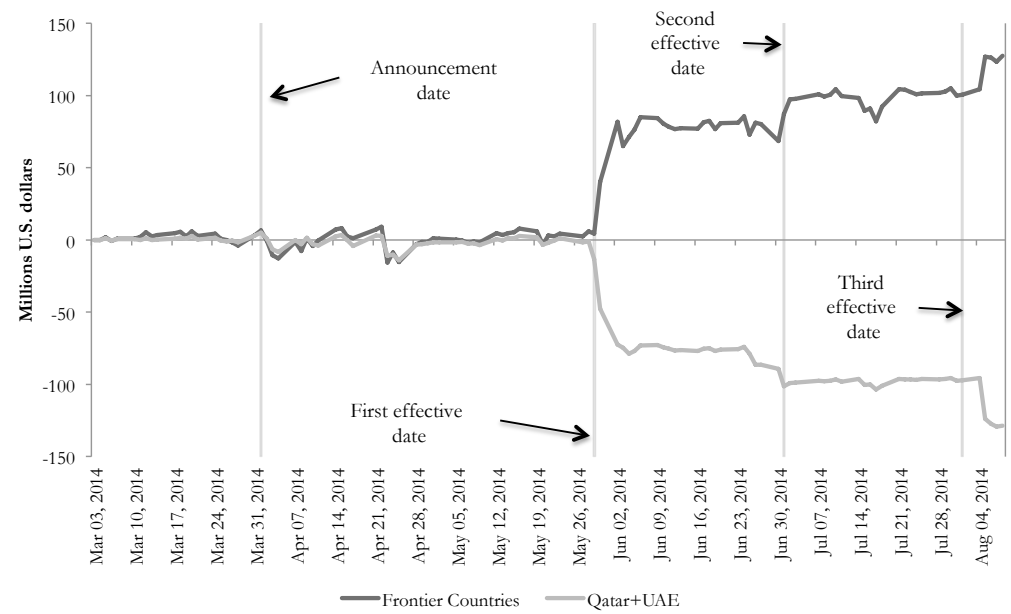

B. Announcement Date

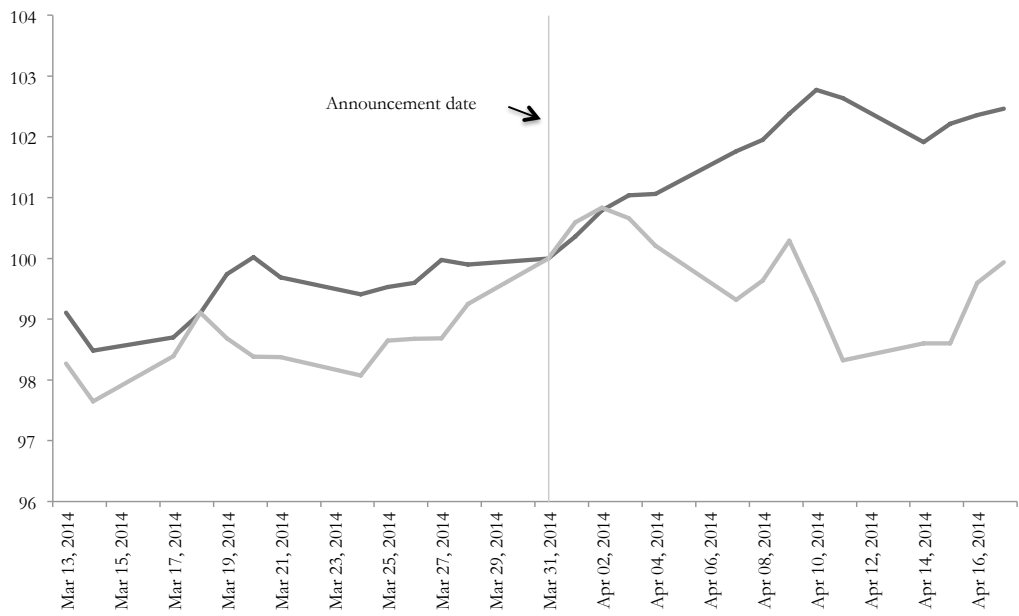

C. Effective Date

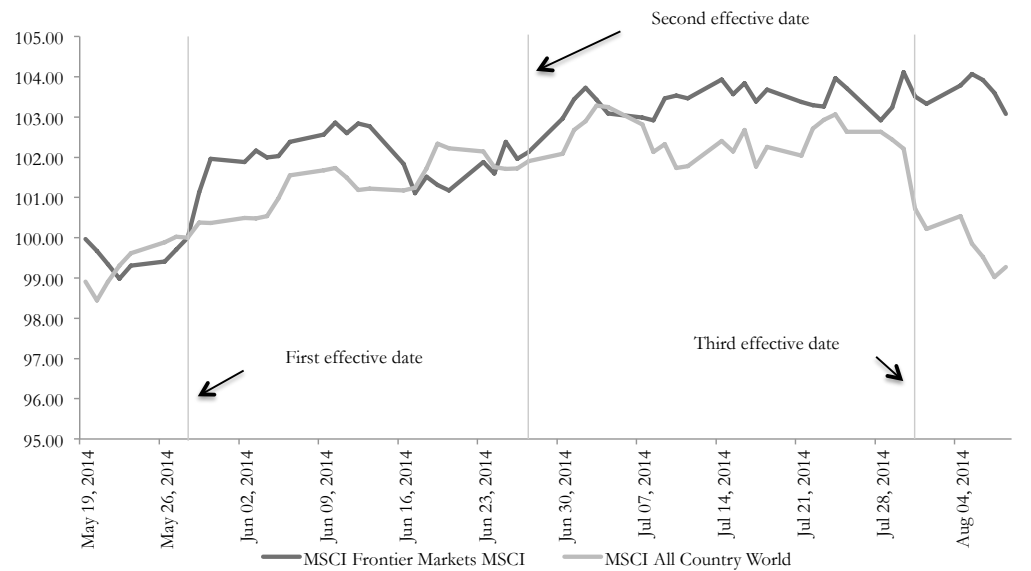


Table 1

Weights vs. Benchmark Weights

This table presents OLS regressions of mutual fund country weights against benchmark country weights with different sets of fixed effects and control variables. Panel A displays results for equity funds and Panel B for bond funds. Funds are divided by their active share classification. Results are presented in levels. Estimations in levels do not contain observations where both weights and benchmark weights are zero. The industry weights are the median weight in a certain country at a certain point in time for different segments of the mutual funds industry. Standard errors are in parenthesis and clustered at the benchmark-time level. *,**, and *** denote statistical significance at 10,5 , and 1 percent, respectively.

\begin{tabular}{|c|c|c|c|c|c|}
\hline \multirow[b]{2}{*}{ Explanatory Variables } & \multirow[b]{2}{*}{ Total Sample } & \multicolumn{4}{|c|}{ Active Share Classification } \\
\hline & & $\begin{array}{r}\text { Explicit } \\
\text { Indexing }\end{array}$ & $\begin{array}{r}\text { Closet } \\
\text { Indexing }\end{array}$ & $\begin{array}{l}\text { Mildly } \\
\text { Active }\end{array}$ & Truly Active \\
\hline \multicolumn{6}{|c|}{ A. Equity Funds } \\
\hline \multicolumn{6}{|c|}{ Dependent Variable: Weights } \\
\hline Benchmark Weights & $\begin{array}{l}0.773^{* * *} \\
(0.008)\end{array}$ & $\begin{array}{l}0.921 \text { *** } \\
(0.013)\end{array}$ & $\begin{array}{l}0.919 * * * \\
(0.011)\end{array}$ & $\begin{array}{l}0.819^{* * *} \\
(0.010)\end{array}$ & $\begin{array}{l}0.499 * * * \\
(0.009)\end{array}$ \\
\hline Fund-Country Fixed Effects & Yes & Yes & Yes & Yes & Yes \\
\hline Fund-Time Fixed Effects & Yes & Yes & Yes & Yes & Yes \\
\hline Country-Time Fixed Effects & No & No & No & No & No \\
\hline Number of Observations & $2,524,798$ & 42,029 & 577,241 & 988,198 & 917,330 \\
\hline R-Squared & 0.912 & 0.989 & 0.966 & 0.907 & 0.842 \\
\hline \multicolumn{6}{|c|}{ Dependent Variable: Weights } \\
\hline Benchmark Weights & $\begin{array}{l}0.673 \text { *** } \\
(0.011)\end{array}$ & $\begin{array}{c}0.846^{* * *} \\
(0.018)\end{array}$ & $\begin{array}{l}0.890 \text { *** } \\
(0.012)\end{array}$ & $\begin{array}{l}0^{0.648} \text { **** } \\
(0.014)\end{array}$ & $\begin{array}{l}0^{0.347} \text { *** }^{\text {** }} \\
(0.011)\end{array}$ \\
\hline Industry Weights & $\begin{array}{l}0.358 \text { *** } \\
(0.011)\end{array}$ & $\begin{array}{l}0.196 \text { *** } \\
(0.023)\end{array}$ & $\begin{array}{l}0.168 \text { *** } \\
(0.017)\end{array}$ & $\begin{array}{l}0.444 \text { *** } \\
(0.013)\end{array}$ & $\begin{array}{l}0.497 \text { *** } \\
(0.011)\end{array}$ \\
\hline Fund-Country Fixed Effects & Yes & Yes & Yes & Yes & Yes \\
\hline Fund-Time Fixed Effects & Yes & Yes & Yes & Yes & Yes \\
\hline Country-Time Fixed Effects & No & No & No & No & No \\
\hline Number of Observations & $2,524,798$ & 42,029 & 577,241 & 988,198 & 917,330 \\
\hline R-Squared & 0.914 & 0.989 & 0.967 & 0.910 & 0.845 \\
\hline \multicolumn{6}{|c|}{ Dependent Variable: Weights } \\
\hline Benchmark Weights & $\begin{array}{l}c_{0.743} \text { *** } \\
(0.010)\end{array}$ & $\begin{array}{l}0.981 \text { *** } \\
(0.018)\end{array}$ & $\begin{array}{l}0.928 \text { *** } \\
(0.009)\end{array}$ & $\begin{array}{l}0_{0.680} \text { *** } \\
(0.017)\end{array}$ & $\begin{array}{l}0.423 \text { *** } \\
(0.014)\end{array}$ \\
\hline Fund-Country Fixed Effects & Yes & Yes & Yes & Yes & Yes \\
\hline Fund-Time Fixed Effects & No & No & No & No & No \\
\hline Country-Time Fixed Effects & Yes & Yes & Yes & Yes & Yes \\
\hline Number of Observations & $1,665,785$ & 37,764 & 458,745 & 657,672 & 511,604 \\
\hline R-Squared & 0.929 & 0.997 & 0.976 & 0.922 & 0.864 \\
\hline \multicolumn{6}{|c|}{ Dependent Variable: Changes in Weights } \\
\hline Changes in Benchmark Weights & $\begin{array}{l}0^{0.679} * * * \\
(0.011)\end{array}$ & $\begin{array}{l}c^{0.792} \text { *** } \\
(0.016)\end{array}$ & $\begin{array}{l}c^{0.787} 7^{* * *} \\
(0.015)\end{array}$ & $\begin{array}{l}0.726 \text { *** } \\
(0.014)\end{array}$ & $\begin{array}{l}0^{0.522} \text { **** } \\
(0.011)\end{array}$ \\
\hline Fund-Country Fixed Effects & Yes & Yes & Yes & Yes & Yes \\
\hline Fund-Time Fixed Effects & Yes & Yes & Yes & Yes & Yes \\
\hline Number of Observations & $2,166,004$ & 35,647 & 483,721 & 858,626 & 788,010 \\
\hline R-Squared & 0.113 & 0.481 & 0.162 & 0.108 & 0.089 \\
\hline \multicolumn{6}{|c|}{ B. Bond Funds } \\
\hline \multicolumn{6}{|c|}{ Dependent Variable: Weights } \\
\hline Benchmark Weights & $0.697 * * *$ & $0.424 * * *$ & $0.935^{* * *}$ & $0.843 * * *$ & $0.223 * * *$ \\
\hline & $(0.022)$ & $(0.032)$ & $(0.015)$ & $(0.023)$ & $(0.040)$ \\
\hline Fund-Country Fixed Effects & Yes & Yes & Yes & Yes & Yes \\
\hline Fund-Time Fixed Effects & Yes & Yes & Yes & Yes & Yes \\
\hline Number of Observations & 153,402 & 723 & 57,338 & 57,335 & 38,006 \\
\hline R-Squared & 0.750 & 0.991 & 0.834 & 0.741 & 0.689 \\
\hline & Depende & riable: Weights & & & \\
\hline Benchmark Weights & $\begin{array}{l}0.369 \text { *** } \\
(0.025)\end{array}$ & $\begin{array}{l}c_{0.466}^{* * *} \\
(0.075)\end{array}$ & $\begin{array}{l}0.552 \text { *** } \\
(0.034)\end{array}$ & $\begin{array}{l}c_{0.328} * * * \\
(0.035)\end{array}$ & $\begin{array}{r}0.027 \\
(0.053)\end{array}$ \\
\hline Industry Weights & $\begin{array}{l}0.378 \text { *** } \\
(0.018)\end{array}$ & $\begin{array}{l}0.133 \text { *** } \\
(0.030)\end{array}$ & $\begin{array}{l}0.349 \text { *** } \\
(0.022)\end{array}$ & $\begin{array}{l}0.430 \text { *** } \\
(0.026)\end{array}$ & $\begin{array}{l}0.348 \text { *** } \\
(0.039)\end{array}$ \\
\hline Fund-Country Fixed Effects & Yes & Yes & Yes & Yes & Yes \\
\hline Fund-Time Fixed Effects & Yes & Yes & Yes & Yes & Yes \\
\hline Number of Observations & 76,405 & 606 & 31,835 & 28,851 & 15,113 \\
\hline R-Squared & 0.752 & 0.983 & 0.778 & 0.732 & 0.745 \\
\hline & Depende & riable: Weights & & & \\
\hline Benchmark Weights & $0.412 * * *$ & - & $0.737^{* * *}$ & 0.053 & $0.718^{* * *}$ \\
\hline & $(0.038)$ & - & $(0.052)$ & $(0.050)$ & $(0.085)$ \\
\hline Macro Variables as Controls & No & - & No & No & No \\
\hline Fund-Country Fixed Effects & Yes & - & Yes & Yes & Yes \\
\hline Fund-Time Fixed Effects & No & - & No & No & No \\
\hline Country-Time Fixed Effects & Yes & - & Yes & Yes & Yes \\
\hline Number of Observations & 88,918 & - & 37,132 & 33,577 & 17,533 \\
\hline R-Squared & 0.770 & - & 0.849 & 0.780 & 0.726 \\
\hline & Dependent $\mathrm{Va}$ & Changes in W & & & \\
\hline Changes in Benchmark Weights & $0.517 * * *$ & $0.347^{* * *}$ & $0.576^{* * *}$ & $0.499 * * *$ & $0.421 * * *$ \\
\hline & $(0.038)$ & $(0.054)$ & $(0.053)$ & $(0.047)$ & $(0.102)$ \\
\hline Fund-Country Fixed Effects & Yes & Yes & Yes & Yes & Yes \\
\hline Fund-Time Fixed Effects & Yes & Yes & Yes & Yes & Yes \\
\hline Number of Observations & 77,386 & 635 & 32,409 & 29,076 & 15,266 \\
\hline R-Squared & 0.156 & 0.241 & 0.116 & 0.142 & 0.196 \\
\hline
\end{tabular}


Table 2

\section{Log Difference Country Benchmark Weights}

This table shows the results of ordinary least squares regressions of the log difference of country benchmark weights on relative returns. Panel A shows results for equity benchmarks and Panel B for bond benchmarks. Relative returns are the difference between country net returns and benchmark net returns, expressed as decimals. Estimations are performed at different frequencies and include different combinations of fixed effects. Only countries in the benchmark are considered for each estimation. Standard errors are in parenthesis and clustered at the benchmark-time level. *, **, and $* * *$ denote statistical significance at 10,5 , and 1 percent, respectively.

\begin{tabular}{|c|c|c|c|c|c|c|c|c|}
\hline \multirow[b]{2}{*}{ Explanatory Variables } & \multicolumn{8}{|c|}{ Dependent Variable: Log Difference Country Benchmark Weights } \\
\hline & \multicolumn{5}{|c|}{ Monthly } & \multirow[t]{2}{*}{ Semiannual } & \multirow[t]{2}{*}{ Annual } & \multirow[t]{2}{*}{ Biannual } \\
\hline \multicolumn{6}{|c|}{ A. Equity Benchmarks } & & & \\
\hline Relative Returns & 0.959 *** & $0.960 * * *$ & $0.960 * * *$ & $0.961 * * *$ & 0.932 *** & $0.865^{* * *}$ & 0.830 *** & $0.760 * * *$ \\
\hline & $(0.006)$ & $(0.006)$ & $(0.006)$ & $(0.006)$ & $(0.020)$ & $(0.017)$ & $(0.014)$ & $(0.013)$ \\
\hline Benchmark-Time Fixed Effects & No & Yes & No & Yes & No & No & No & No \\
\hline Benchmark-Country Fixed Effects & No & No & Yes & Yes & Yes & Yes & Yes & Yes \\
\hline Country-Time Fixed Effects & No & No & No & No & Yes & Yes & Yes & Yes \\
\hline Number of Observations & 98,549 & 98,549 & 98,549 & 98,549 & 98,549 & 93,704 & 88,751 & 79,687 \\
\hline R-Squared & 0.307 & 0.366 & 0.321 & 0.379 & 0.600 & 0.665 & 0.766 & 0.900 \\
\hline \multicolumn{9}{|c|}{ B. Bond Benchmarks } \\
\hline Relative Returns & $\begin{array}{l}1.024^{* * * *} \\
(0.035)\end{array}$ & $\begin{array}{l}1^{1.022} \text { *** } \\
(0.032)\end{array}$ & $\begin{array}{l}1_{1.028^{* * * *}} \\
(0.034)\end{array}$ & $\begin{array}{l}1^{1.027} \text { *** } \\
(0.031)\end{array}$ & $\begin{array}{l}c^{0.731} \text { *** } \\
(0.020)\end{array}$ & $\begin{array}{l}1^{1.065^{* * *}} \\
(0.160)\end{array}$ & $\begin{array}{l}1_{1.444}^{* * * *} \\
(0.143)\end{array}$ & $\begin{array}{l}1^{1.778^{* * *}} \\
(0.126)\end{array}$ \\
\hline Benchmark-Time Fixed Effects & No & Yes & No & Yes & No & No & No & No \\
\hline Benchmark-Country Fixed Effects & No & No & Yes & Yes & Yes & Yes & Yes & Yes \\
\hline Country-Time Fixed Effects & No & No & No & No & Yes & Yes & Yes & Yes \\
\hline Number of Observations & 10,076 & 10,076 & 10,076 & 10,076 & 10,076 & 9,430 & 8,689 & 7,331 \\
\hline R-Squared & 0.184 & 0.204 & 0.204 & 0.224 & 0.915 & 0.941 & 0.958 & 0.970 \\
\hline
\end{tabular}


Table 3

\section{Weights vs. Benchmark Weights: Exogenous Events}

The top part of each panel in this table presents OLS regressions of mutual fund country weights against benchmark country weights and the residual between benchmark weights and buy-and-hold benchmark weights (exogenous component), with different sets of fixed effects. The middle (bottom) part for equity (bond) funds shows regressions dividing the coefficients between no-event and exogenous event times. Exogenous event times are those beyond the 25th and 75th tails of the distribution of the sample during the months that MSCI revises the indexes. No-event times are observations within those tails plus all the months with no revisions. Test difference coefficients is a linear tests with the difference of coefficients for normal and event times. All regressions are estimated in differences. The bottom part for equity funds reports OLS regressions for equity funds of the changes in mutual fund country weights against the changes in buy-and-hold benchmark weights and the changes in the exogenous component, with different sets of fixed effects. The estimations are only for December 2001-June 2002, when MSCI conducted changes in the construction of its equity indexes. Panel A displays results for equity funds and Panel B for bond funds. Funds are divided by their active share classification. Results are presented in levels and in differences. Estimations in levels do not contain observations where both weights and benchmark weights are zero. Standard errors are in parenthesis and clustered at the benchmark-time level.*, ${ }^{* *}$, and ${ }^{* * *}$ denote statistical significance at 10,5 , and 1 percent, respectively.

\begin{tabular}{|c|c|c|c|c|c|}
\hline \multirow[b]{2}{*}{ Explanatory Variables } & \multirow[b]{2}{*}{ Total Sample } & \multicolumn{4}{|c|}{ Active Share Classification } \\
\hline & & $\begin{array}{r}\text { Explicit } \\
\text { Indexing }\end{array}$ & $\begin{array}{r}\text { Closet } \\
\text { Indexing } \\
\end{array}$ & $\begin{array}{l}\text { Mildly } \\
\text { Active }\end{array}$ & Truly Active \\
\hline \multicolumn{6}{|c|}{ A. Equity Funds } \\
\hline \multicolumn{6}{|c|}{ Dependent Variable: Changes in Weights } \\
\hline Change in Buy-and-Hold Benchmark Weight & $\begin{array}{l}c_{0.707}^{* * *} \\
(0.016)\end{array}$ & $\begin{array}{l}c^{0.816} \text { *** } \\
(0.029)\end{array}$ & $\begin{array}{l}c_{0.847}^{* * *} \\
(0.023)\end{array}$ & $\begin{array}{l}c_{0.712}^{* * *} \\
(0.023)\end{array}$ & $\begin{array}{l}0.511 \text { *** } \\
(0.015)\end{array}$ \\
\hline Change in Exogenous Component & $\begin{array}{l}0.378 \text { *** } \\
(0.034)\end{array}$ & $\begin{array}{l}0.505 \text { *** } \\
(0.034)\end{array}$ & $\begin{array}{l}0.477 \text { *** } \\
(0.050)\end{array}$ & $\begin{array}{l}0.371 \text { *** } \\
(0.042)\end{array}$ & $\begin{array}{l}0.253 \text { *** } \\
(0.025)\end{array}$ \\
\hline Fund-Country Fixed Effects & Yes & Yes & Yes & Yes & Yes \\
\hline Fund-Time Fixed Effects & Yes & Yes & Yes & Yes & Yes \\
\hline Number of Observations & $2,092,625$ & 34,739 & 479,150 & 834,466 & 744,270 \\
\hline R-Squared & 0.086 & 0.237 & 0.157 & 0.080 & 0.055 \\
\hline \multicolumn{6}{|c|}{ Dependent Variable: Change in Weights } \\
\hline Change in Benchmark Weights*Normal Times & $\begin{array}{l}0^{0.720} \text { *** } \\
(0.030)\end{array}$ & $\begin{array}{l}0^{0.923} \text { *** } \\
(0.083)\end{array}$ & $\begin{array}{l}c^{0.851}{ }^{* * *} \\
(0.048)\end{array}$ & $\begin{array}{l}0^{0.740}{ }^{* * *} \\
(0.043)\end{array}$ & $\begin{array}{c}c_{0.557}^{* * *} \\
(0.042)\end{array}$ \\
\hline Change in Benchmark Weights*Event Times & $\begin{array}{l}0.651 \text { *** } \\
(0.022)\end{array}$ & $\begin{array}{l}0.731 \text { *** } \\
(0.030)\end{array}$ & $\begin{array}{l}0.746 \text { *** } \\
(0.028)\end{array}$ & $\begin{array}{l}0.625 \text { *** } \\
(0.029)\end{array}$ & $\begin{array}{l}0.526 \text { *** } \\
(0.022)\end{array}$ \\
\hline Fund-Country Fixed Effects & Yes & Yes & Yes & Yes & Yes \\
\hline Fund-Time Fixed Effects & Yes & Yes & Yes & Yes & Yes \\
\hline Number of Observations & $1,583,029$ & 36,498 & 443,711 & 627,069 & 475,751 \\
\hline R-Squared & 0.925 & 0.995 & 0.969 & 0.910 & 0.867 \\
\hline Test of Difference in Coefficients & $0.069 * *$ & $0.192 * *$ & $0.105 *$ & $0.115 * *$ & 0.031 \\
\hline \multicolumn{6}{|c|}{ Dependent Variable: Changes in Weights } \\
\hline \multirow[t]{2}{*}{ Changes in Buy-and-Hold Benchmark Weight } & $0.707 * * *$ & - & $0.837 * * *$ & $0.709 * * *$ & $0.644 * * *$ \\
\hline & $(0.093)$ & - & $(0.116)$ & $(0.217)$ & $(0.182)$ \\
\hline \multirow[t]{2}{*}{ Changes in Exogenous Component } & $0.904 * * *$ & - & $1.081 * * *$ & $1.022 * * *$ & $0.483 * * *$ \\
\hline & $(0.248)$ & - & $(0.303)$ & $(0.367)$ & $(0.118)$ \\
\hline Fund-Country Fixed Effects & Yes & - & Yes & Yes & Yes \\
\hline Fund-Time Fixed Effects & Yes & - & Yes & Yes & Yes \\
\hline Number of Observations & 3,387 & - & 934 & 1,553 & 885 \\
\hline$\underline{\text { R-Squared }}$ & 0.701 & - & 0.665 & 0.717 & 0.739 \\
\hline \multicolumn{6}{|c|}{ B. Bond Funds } \\
\hline \multicolumn{6}{|c|}{ Dependent Variable: Change in Weights } \\
\hline \multirow[t]{2}{*}{ Change in Buy-and-Hold Benchmark Weight } & $0.477 * * *$ & - & $0.598 * * *$ & $0.428 * * *$ & $0.290 *$ \\
\hline & $(0.051)$ & - & $(0.060)$ & $(0.053)$ & $(0.155)$ \\
\hline \multirow[t]{2}{*}{ Change in Exogenous Component } & $0.409 * * *$ & - & $0.542 * * *$ & $0.385 * * *$ & 0.142 \\
\hline & $(0.048)$ & - & $(0.059)$ & $(0.051)$ & $(0.133)$ \\
\hline Fund-Country Fixed Effects & Yes & - & Yes & Yes & Yes \\
\hline Fund-Time Fixed Effects & Yes & - & Yes & Yes & Yes \\
\hline Number of Observations & 70,924 & - & 29,603 & 26,552 & 14,165 \\
\hline R-Squared & 0.298 & - & 0.115 & 0.134 & 0.450 \\
\hline \multicolumn{6}{|c|}{ Dependent Variable: Change in Weights } \\
\hline \multirow[t]{2}{*}{ Change in Benchmark Weights*Normal Times } & $0.758 * * *$ & - & $0.960 * * *$ & $0.835 * * *$ & 0.319 \\
\hline & $(0.148)$ & - & $(0.167)$ & $(0.237)$ & $(0.292)$ \\
\hline \multirow[t]{2}{*}{ Change in Benchmark Weights*Event Times } & $0.320 * * *$ & - & $0.489 * * *$ & $0.233 * * *$ & 0.064 \\
\hline & $(0.052)$ & - & $(0.061)$ & $(0.051)$ & $(0.178)$ \\
\hline Fund-Country Fixed Effects & Yes & - & Yes & Yes & Yes \\
\hline Fund-Time Fixed Effects & Yes & - & Yes & Yes & Yes \\
\hline Number of Observations & 84,913 & - & 35,594 & 32,058 & 16,621 \\
\hline R-Squared & 0.227 & - & 0.199 & 0.119 & 0.299 \\
\hline Test of Difference in Coefficients & $0.438 * * *$ & - & $0.471 * * *$ & $0.602 * *$ & 0.255 \\
\hline
\end{tabular}




\section{Table 4}

\section{Capital Flows Variance Descomposition}

This table presents the variance descomposition of capital flows from mutual funds into four components. Benchmark flows is the estimated alpha times benchmark weight multiplied by fund flows. Active flows is the difference between the weight and benchmark weight multiplied by the estimated alpha, times fund flows. Benchmark reallocation is the past assets multiplied by fund returns times the estimated alpha multiplied by the difference between the benchmark weight and the buy-and-hold benchmark weight. Active reallocation is the difference between the active weight and the active buy-and-hold weight multiplied by lagged assets times fund returns. For each exercise, we construct the total capital flows (and components) within each country-date. Then, we obtain the variance at the country level, imputing equally the covariances across the four components and we present the average and median share explained by each component. Panel A presents results for the total sample. Panel B shows results for normal times. Panel C displays results for months with index rebalancing. Panel D depicts results for the months of the MSCI methodological change during 2001 and 2002.

\begin{tabular}{|c|c|c|c|c|c|c|}
\hline Sample & $\begin{array}{c}\text { Benchmark } \\
\text { Flows }\end{array}$ & $\begin{array}{l}\text { Active } \\
\text { Flows } \\
\end{array}$ & $\begin{array}{c}\text { Benchmark } \\
\text { Reallocation }\end{array}$ & $\begin{array}{c}\text { Active } \\
\text { Reallocation }\end{array}$ & $\begin{array}{c}\text { Total Benchmark } \\
(1)+(3)\end{array}$ & $\begin{array}{c}\text { Total Active } \\
(2)+(4)\end{array}$ \\
\hline \multicolumn{7}{|c|}{ A. Total Sample } \\
\hline All Funds & 16.1 & 4.6 & 22.6 & 56.7 & 38.7 & 61.3 \\
\hline Explicit Indexing & 50.7 & 3.7 & 17.1 & 28.5 & 67.8 & 32.2 \\
\hline Closet Indexing & 21.1 & 1.8 & 15.0 & 62.0 & 36.1 & 63.9 \\
\hline Mildly Active & 12.7 & 3.2 & 21.0 & 63.2 & 33.7 & 66.3 \\
\hline Truly Active & 7.9 & 9.0 & 12.3 & 70.8 & 20.2 & 79.8 \\
\hline
\end{tabular}

\section{B. Normal Times}

\begin{tabular}{|c|c|c|c|c|c|c|}
\hline All Funds & 9.4 & 7.5 & 4.9 & 78.2 & 14.3 & 85.7 \\
\hline Explicit Indexing & 49.6 & 5.3 & 13.3 & 31.8 & 62.9 & 37.1 \\
\hline Closet Indexing & 8.1 & 2.2 & 4.5 & 85.2 & 12.6 & 87.4 \\
\hline Mildly Active & 4.6 & 6.0 & 6.9 & 82.6 & 11.4 & 88.6 \\
\hline Truly Active & 1.5 & 15.4 & 2.3 & 80.9 & 3.8 & 96.2 \\
\hline
\end{tabular}

C. Event Times

\begin{tabular}{|c|c|c|c|c|c|c|}
\hline All Funds & 48.6 & 3.1 & 24.1 & 24.2 & 72.7 & 27.3 \\
\hline Explicit Indexing & 62.6 & 0.5 & 15.1 & 21.8 & 77.7 & 22.3 \\
\hline Closet Indexing & 22.6 & 2.2 & 18.8 & 56.4 & 41.4 & 58.6 \\
\hline Mildly Active & 13.6 & 3.0 & 23.6 & 59.7 & 37.2 & 62.8 \\
\hline Truly Active & 8.9 & 8.8 & 14.0 & 68.3 & 22.9 & 77.1 \\
\hline
\end{tabular}

\section{MSCI Index Rebalancing}

\begin{tabular}{|c|c|c|c|c|c|c|}
\hline All Funds & 5.8 & 3.7 & 32.7 & 57.8 & 38.5 & 61.5 \\
\hline Explicit Indexing & 8.3 & 1.1 & 34.8 & 55.7 & 43.1 & 56.9 \\
\hline Closet Indexing & 5.7 & 0.8 & 27.9 & 65.6 & 33.6 & 66.4 \\
\hline Mildly Active & 8.6 & 4.8 & 33.4 & 53.1 & 42.0 & 58.0 \\
\hline Truly Active & 1.3 & 3.6 & 19.0 & 76.1 & 20.3 & 79.7 \\
\hline
\end{tabular}


Table 5

Event Study Analysis: Cumulative Returns

This table presents the results from an event study of all episodes of large benchmark changes. All returns are cumulative returns starting at the first day presented in the table. Raw returns are the net returns of the stock/debt market index or the exchange rate for the country. Excess returns are returns minus a global factor. ple

$\lim$

Asset Prices

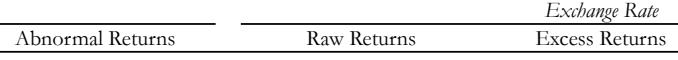
Abnormal Returns A. Announcement $\left(T_{A}\right)$ and Effective Date $\left(T_{E}\right)$

Returns on $\left(\mathrm{T}_{\mathrm{A}}-2\right)$ and Returns on $(\mathrm{TE}-12)$

Cumulative Returns between $\left(T_{-}-2\right)$ and $\left(T_{N}\right)$ and Cumulative Returns between $\left(T_{\mathrm{E}}-12\right)$ and $\left(\mathrm{T}_{\mathrm{E}}-10\right)$

0.05
$(0.261)$
$0.788 * * *$
$(0.262)^{*}$
$1.244 * * *$
$(0.307)$ ***
$2.356 * * *$
$(0.430)$
$2.621 * * *$
$(0.507)$
$2.224 * * *$
$(0.544)$
79

$\begin{array}{cc}-0.339 & -0.223 \\ (0.242) & (0.211) \\ 0.205 & 0.431 * * \\ (0.214) & (0.220) \\ 0.583 * * & 0.745 * * \\ (0.276) & (0.274) \\ 1.932 * * * & 1.884 * * \\ (0.384) & (0.408) \\ 1.521 * * * & 1.833 * * \\ (0.502) & (0.522) \\ 1.325 * * * & 1.34 * * \\ (0.583) & (0.655)\end{array}$

B. Announcement Date (T) Number of Observations

B. Announcement Date $\left(\mathrm{T}_{\mathrm{A}}\right)$
$\overline{\text { Returns on }\left(\mathrm{T}_{\mathrm{A}}-2\right)}$

Cumulative Returns between $\left(T_{A}-2\right)$ and $\left(T_{A}\right)$

Cumulative Returns between $\left(\mathrm{T}_{A}-2\right)$ and $\left(\mathrm{T}_{A}+5\right)$

Cumulative Returns between $\left(\mathrm{T}_{\Lambda}-2\right)$ and $\left(\mathrm{T}_{A}+10\right)$

Cumulative Returns between $\left(T_{A}-2\right)$ and $\left(T_{A}+15\right)$

Cumulative Returns between $\left(\mathrm{T}_{A}-2\right)$ and $\left(\mathrm{T}_{\Lambda}+20\right)$ Number of Observations

$\begin{array}{rrr}-0.025 & -0.346 & -0.155 \\ (0.193) & (0.187) & (0.179) \\ 1.27 & 0.6350 \times & 0.925\end{array}$

$1.27 * * * \quad 0.613 * * *$

$(0.278) \quad(0.239)$

${ }_{1.43 * * *}^{(0.278)}$

$(0.340)$

$1.709 * * *$

$(0.592)+(0.490)$

$2.302 * * 1.678 *$

$\begin{array}{ll}(0.647) & (0.609) \\ 1.94 * * * & 1.431 * *\end{array}$

$(0.637) \quad(0.684)$

C. Effective Date $\left(\mathrm{T}_{\mathrm{T}}\right)$

Returns on $\left(T_{\mathrm{E}}-12\right)$
Cumulative Returns between $\left(T_{\mathrm{E}-12}\right)$ and $\left(\mathrm{T}_{\mathrm{E}}-10\right)$

Cumulative Returns between $\left(\mathrm{T}_{\mathrm{L}}-12\right)$ and $\left(\mathrm{T}_{\mathrm{E}}-5\right)$

Cumulative Returns between $\left(T_{\mathrm{E}}-12\right)$ and $\left(\mathrm{T}_{\mathrm{E}}\right)$

Cumulative Returns between $\left(T_{\mathrm{E}}-12\right)$ and $\left(\mathrm{T}_{\mathrm{E}}+5\right)$

Cumulative Returns between $\left(\mathrm{T}_{\mathrm{E}}-12\right)$ and $\left(\mathrm{T}_{\mathrm{E}}+10\right)$

$\begin{array}{cc}-0.045 & -0.36 \\ (0.363) & (0.319) \\ 0.082 & -0.369 \\ (0.483) & (0.371) \\ 0.974 * * & -0.104 \\ (0.574) & (0.474) \\ 4.348 * * * & 3.174 \\ (0.893) & (1.008) \\ 3.090 * * * & 1.301 \\ (0.820) & (0.862) \\ 2.64 * * * & 1.174 \\ (0.972) & (1.034) \\ 32 & \end{array}$

$\begin{array}{cc}-0.266 & -0.377 \\ (0.319) & (0.317) \\ -0.369 & -0.278 \\ (0.371) & (0.401) \\ -0.104 & 0.31 \\ (0.474) & (0.483) \\ 3.174 * * * & 3.543 * * \\ (1.008) & (1.074) \\ 1.301 * & 2.185 * * \\ (0.862) & (0.856) \\ 1.174 & 1.576 * \\ (1.034) & (1.203) \\ 32 & 32\end{array}$

Number of Observations

$(0.972)$
32

$-0.155$

$\begin{array}{rrrr} & & & \\ -0.155 & -0.006 & 0.004 & -0.041 \\ (0.179) & (0.093) & (0.073) & (0.057)\end{array}$

\begin{tabular}{lll}
\multicolumn{1}{c}{0.04} & 0.063 & 0.172 \\
$(0.110)$ & $(0.071)$ & $(0.194)$ \\
$-0.266 * * *$ & $-0.292 * * *$ & $-0.326 * * *$ \\
$(0.103)$ & $(0.091)$ & $(0.102)$ \\
$-0.274 * *$ & $-0.204 * *$ & $-0.247 * *$ \\
$(0.125)$ & $(0.107)$ & $(0.119)$ \\
$-0.610 * * *$ & $-0.529 * * *$ & $-0.51 * * *$ \\
$(0.199)$ & $(0.166)$ & $(0.191)$ \\
$-0.489 * *$ & $-0.358 * *$ & -0.319 \\
$(0.249)$ & $(0.219)$ & $(0.261)$ \\
-0.141 & -0.184 & -0.229 \\
$(0.254)$ & $(0.231)$ & $(0.274)$ \\
65 & 65 & 65 \\
\hline
\end{tabular}

$\begin{array}{llll}(0.179) & (0.093) & (0.073) & (0.057) \\ 0.925 * * & -0.329 * * & -0.394 * * & -0.447 * *\end{array}$

$-0.394 * * *-0.447 *$

$\begin{array}{cccc}(0.222) & (0.150) & (0.130) & (0.144) \\ 1.048 * * & -0.245 * & -0.171 & -0.273 * \\ (0.317) & (0.178) & (0.15) & (176)\end{array}$

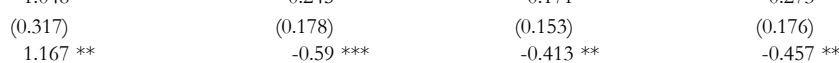

$\begin{array}{lll}0.520) & (0.233) & (0.171)\end{array}$

$\begin{array}{llll}(0.520) & (0.233) & (0.171) & (0.217) \\ 1.587 * * & -0.513 * * & -0.411 * * & -0.465 * \\ (0.662) & (0.271) & (0.239) & (0.309)\end{array}$

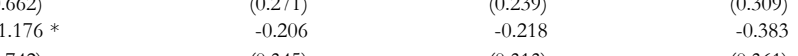

\begin{tabular}{rrrr}
$(0.742)$ & $(0.345)$ & $(0.313)$ & $(0.361)$ \\
47 & 39 & 39 & 39 \\
\hline
\end{tabular}

$\begin{array}{cccc} & & & \\ -0.377 & -0.063 & 0.035 & 0.307 \\ (0.317) & (0.079) & (0.057) & (0.231) \\ -0.278 & -0.172 * & -0.141 & -0.142 \\ (0.401) & (0.127) & (0.116) & (0.132) \\ 0.31 & -0.317 * * & -0.252 * * & -0.208 * \\ (0.483) & (0.167) & (0.140) & (0.139) \\ 3.543 * * * & -0.608 * * & -0.679 * * & -0.54 * \\ (1.074) & (0.354) & (0.305) & (0.296) \\ 2.185 * * * & -0.452 & -0.779 & -0.097 \\ (0.856) & (0.479) & (0.419) & (0.465) \\ 1.576 * & -0.043 & -0.134 & 0.021 \\ (1.203) & (0.375) & (0.343) & (0.425) \\ 32 & 26 & 26 & 26 \\ & & & \end{array}$




\section{Appendix 1. Benchmark and portfolio choice}

This appendix briefly summarizes the determinants of the relation between benchmarks and actual portfolios, starting from the literature on portfolio allocations under benchmark or tracking error constraints. This framework might help understand and interpret the results presented in the paper.

Consider the problem faced by the manager of fund $i$ that is deciding his portfolio allocation across a set of $N$ assets, in our case $N$ different countries. The manager's performance is measured against that of a benchmark index, whose portfolio allocation across the $N$ countries is given by $w_{i}^{B} \in \mathbb{R}^{N}$, such that $w_{i c}^{B} \in[0,1], c=\{1, \ldots, N\}, \sum_{c=1}^{N} w_{i c}^{B}=1$. The subscript $i$ is used to indicate that the benchmark index corresponds to that tracked by fund $i$ and the subscript $c$ denotes the elements of $w_{i}^{B}$ that index different countries. These properties mean that the benchmark is a long-only portfolio (no short-long strategies are allowed) and that the allocations exhaust all the resources available.

Roll (1992) and Brennan (1993), among others, have shown that a manager with meanvariance preferences relative to the benchmark will choose a portfolio allocation $w_{i}$ that can be expressed as

$$
w_{i c}=w_{i c}^{B}+w_{i c}^{h}
$$

where $w_{i}^{h}$ is a hedge portfolio that is proportional to the difference between the minimum variance portfolio and the portfolio where a line through the minimum variance portfolio intersects the efficient portfolio frontier. For a manager that is constrained to follow long-only portfolios, the hedge portfolio must hold

$$
\begin{gathered}
-w_{i c}^{B} \leq w_{i c}^{h} \leq 1-w_{i c}^{B}, \quad c=\{1, \ldots, N\}, \\
\sum_{j=1}^{N} w_{i c}^{h}=0 .
\end{gathered}
$$

The relative importance of the hedge portfolio depends on the manager's risk aversion, or alternatively on the amount of tracking error (maximum difference between the return of the manager's portfolio and that of the benchmark) that he is allowed (Roll, 1992). Intuitively, the 
less risk averse the manager, or the larger the tracking error, the more relevant is the hedge portfolio and the less relevant is the benchmark for the manager's portfolio.

Assume now that we fit a linear regression by OLS to the relation between the manager's and the benchmark portfolio allocations

$$
w_{i c}=\alpha+\beta w_{i c}^{B}+\varepsilon_{i c} .
$$

As it is well known, the estimated coefficient $\hat{\beta}$ is given by

$$
\hat{\beta}=\frac{\operatorname{Cov}\left(w_{i c}^{B}, w_{i c}\right)}{\operatorname{Var}\left(w_{i c}^{B}\right)}=1+\frac{\operatorname{Cov}\left(w_{i c}^{B}, w_{i c}^{h}\right)}{\operatorname{Var}\left(w_{i c}^{B}\right)}
$$

So, the coefficient will be larger or smaller than one depending on whether the covariance between the benchmark and the hedge portfolio is positive or negative. For instance, if the manager tends to overweight (underweight) the countries with the highest benchmark weights the covariance will be positive (negative) and the coefficient will be larger (smaller) than one.

The long-only constraint imposed on the hedge portfolio biases this covariance to be negative. In fact, assume that the manager chooses the hedge portfolio randomly from a distribution that is symmetric around zero (so that the extent of under or overweighting of a country is unrelated to the benchmark weight), but keeps the draw only if it satisfies the feasibility constraints described in Equation (A3). The higher (lower) the benchmark weight of a country, the higher the probability that a random draw that overweighs (underweights) the country will hit the upper (lower) constraint and has to be replaced. This random selection process will result in draws that make more likely to underweight (overweight) countries with higher (lower) benchmark weights.

The extent of the negative bias depends on the degree that fund managers are active. Following Cremer and Petajisto (2009), we define how active fund managers are by the sum of the absolute value of the portfolio deviations from the benchmark:

$$
\text { Active Share }_{i}=\frac{1}{2} \sum_{c=1}^{N}\left|w_{i c}-w_{i c}^{B}\right|=\frac{1}{2} \sum_{c=1}^{N}\left|w_{i c}^{h}\right|
$$

Equation (A6) can be interpreted as the source of a constraint imposed on the manager or as a result of his willingness to deviate from the benchmark, determined by his degree of risk aversion or tracking error constraint. A less risk averse manager or one allowed more tracking 
error will deviate more from the benchmark and have a higher measured active component. The more the manager tries to deviate from the benchmark, the more likely he will hit one side of the constraints, forcing him to tilt his behavior and inducing a more negative bias. On the contrary, one could always draw the hedge portfolio of a distribution with a variance that is small enough such that the probability of hitting a constraint is negligible, resulting in an estimated coefficient close to one. Such manager will have a very small active component and behave as an index fund.

The coefficient will be zero only when the covariance between the hedge and benchmark portfolios equals minus the variance of the benchmark weight. This means that the linear projection of the hedge portfolio on the benchmark portfolio has a slope equals to negative one. In this sense, the hedge portfolio undoes what the benchmark portfolio does and is a situation akin to having an allocation that does not follow the benchmark.

In the paper, we estimate a series of regressions similar to that presented in Equation (A4), albeit in a panel setting and controlling for many other determinants in a parametric and non-parametric fashion. The coefficient of that regression tells us, on average, how much the weight of a country in a fund portfolio increases when its weight on the benchmark increases, taking into account the correlation between the benchmark and hedge portfolios present in the data. This is the relation of interest from a forecasting perspective, despite the fundamental relation given by Equation (A1). 


\section{Appendix 2. The proliferation of benchmark indexes}

As of May of 2012, there were 267,415 active equity indexes and 63,616 active bond indexes in Datastream, including the many indexes focused on single markets and different industrial sectors. While the number is high, most mutual funds are benchmarked against few and very popular indexes. For instance, the S\&P 500 is the most popular index for U.S. funds, while the MSCI World or MSCI EAFE (Europe, Australasia, and, Far East) are the most prevalent indexes among international funds investing in developed markets.

While there are approximately 18 companies producing bond indexes, many more companies are involved in the production of equity indexes, including the large international indexing companies (such as, FTSE, MSCI, and S\&P), and the national producers of indexes and national stock exchanges. As of December 2012, the largest producer of equity indexes was MSCI with 126,821 indexes, then FTSE with 39,738 indexes, Russell with 27,826 indexes, S\&P 17,723 with indexes, and, Dow Jones with 14,771 indexes. The largest producer of bond indexes was J.P. Morgan with 20,390 indexes, followed by Merrill Lynch with 18,897 indexes, Citigroup with 10,281 indexes, and Barclays Capital with 3,963 indexes. Despite the apparent diversity of indexes, the popularity of indexes is highly skewed, with a few indexes being followed by many investors.

While there are broad indexes such as those focused in world markets, advanced (or developed) markets, emerging markets, frontier markets, or country specific, these are further subdivided by different characteristics. For instance, MSCI has different indexes according to the currency of denomination (e.g., U.S. dollar, euro, local), returns (e.g., net returns, gross returns, total returns), industry, size (e.g., large cap, medium cap, small cap), and style (e.g., value, growth). This generates a wide diversity among indexes, which has been increasing over time.

Benchmark weights are assembled with the portfolio weights of individual securities included in a benchmark index, aggregated at the country level according to the market where the security was issued. That is, international benchmark indexes are typically constructed using a bottom-up approach and consist of composite stock (or bond) market indexes that include securities from many countries as constituents. The following example from MSCI, the provider 
of the most prevalent equity indexes, illustrates more details on how benchmarks are assembled (other companies use a similar approach). ${ }^{1}$

MSCI first defines the main scope of a benchmark index (such as, geography, industry, and type of firms) and in which category each country is classified at each point in time (developed, emerging, or frontier). Then, it selects a number of securities that fall within the scope and meet the size, market capitalization, liquidity, and other requirements. Each of these securities gets a loading (or inclusion factor) in the index portfolio assigned by the index producer according to how much it meets the index-construction criteria and how accessible it is to investors (given by the free-float market capitalization, restrictions to foreign investors, and so forth). The return of the index consists of the returns of its constituent securities, using various approaches to aggregate fluctuations in individual instruments (e.g., Laspeyres, chain-weighting). Namely, each index captures the market capitalization weighted returns of all constituents included in the index. The indexes are periodically rebalanced to ensure their continuity and representativeness (MSCI Barra, 2013a,b). The inclusion/exclusion of a country in an index and its average benchmark weight is correlated with the relative size of the stock market and the economy, plus other institutional factors. 


\section{Online Appendix Figure 1}

\section{Total Net Assets}

This figure shows the average total net assets (TNAs) per year in the database and how these total net assets (TNAs) are distributed among funds with different degree of activism. Panel A shows these figures for equity funds and Panel B for bond funds. Although our data on bond funds start in 1997, for this figure we exclude the years up to 2001 due to the few observations available.

A. Equity Funds
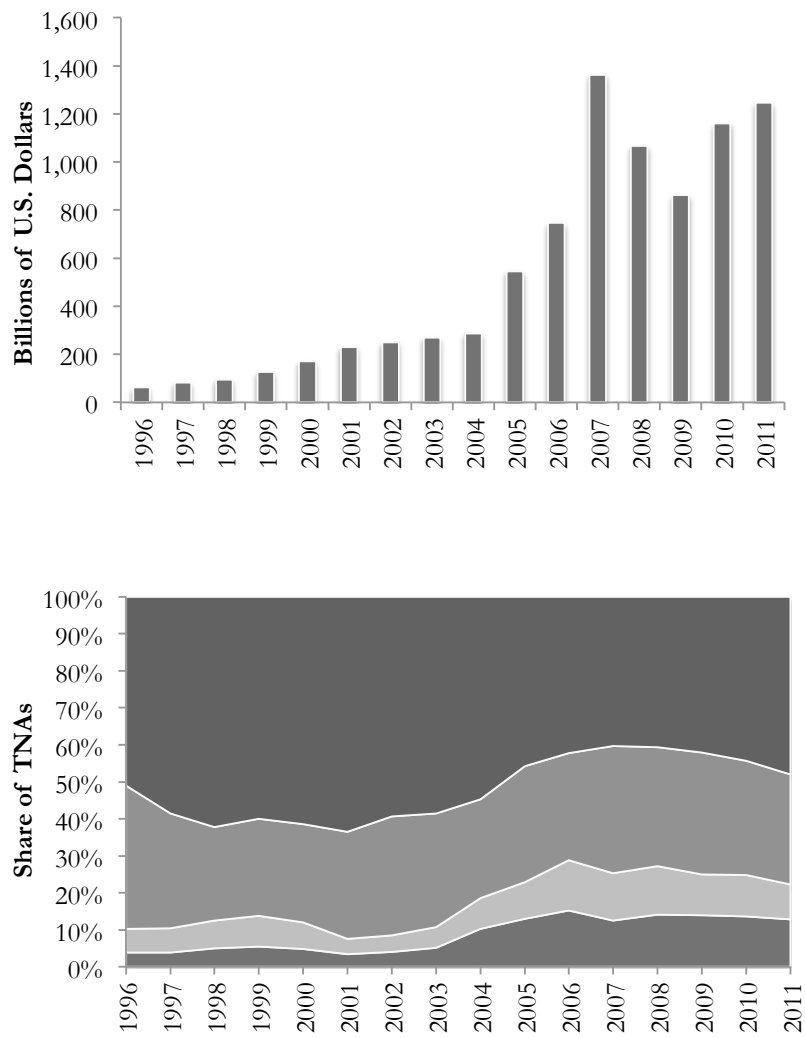

B. Bond Funds
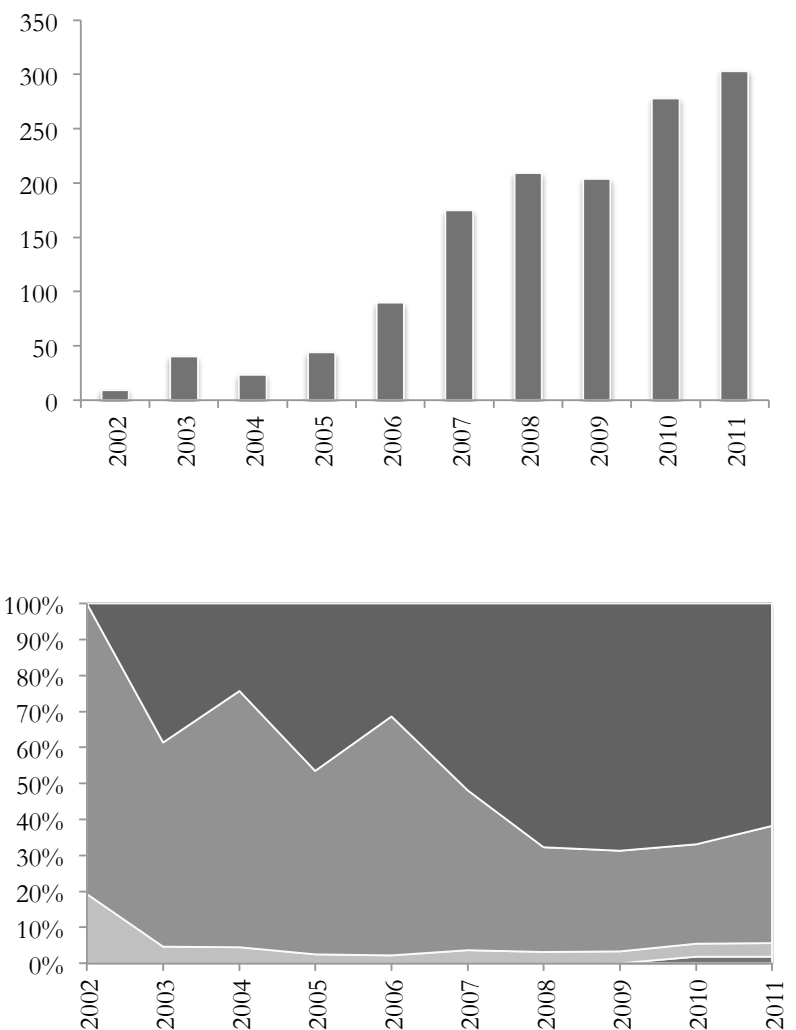

- Truly Active

= Mildly Active

" Closet Indexing

Explicit Indexing 
Online Appendix Figure 2

\section{Identification through Benchmarks}

This figure shows different illustrations of benchmark changes. Panel A shows an ellipse containing 90 percent of the observations of all the pairwise combinations for two different benchmarks for the same country at the same time for annual changes in benchmark weights. Panel B shows the estimated kernel distribution of the change in exogenous component for December 2001 and June 2002 (Exogenous Event MSCI) versus the rest of the sample between 2000 and 2002 (Normal Times). Kernel estimates are Gaussian with a bandwith of 0.85 .

\section{A. Changes vs Changes: Ellipse Encircling 90 Percent of the Observations}

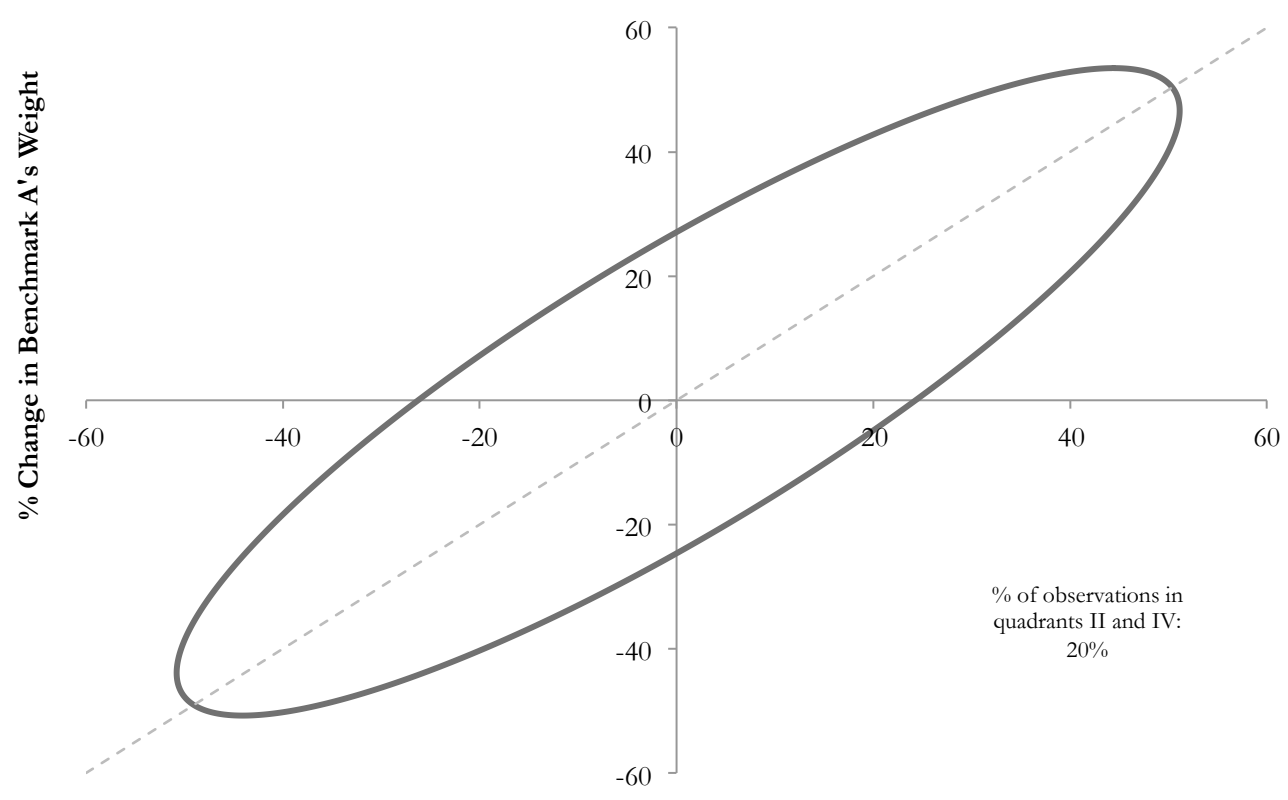

$\%$ Change in Benchmark B's Weight

B. Exogenous MSCI Event: Normal Times

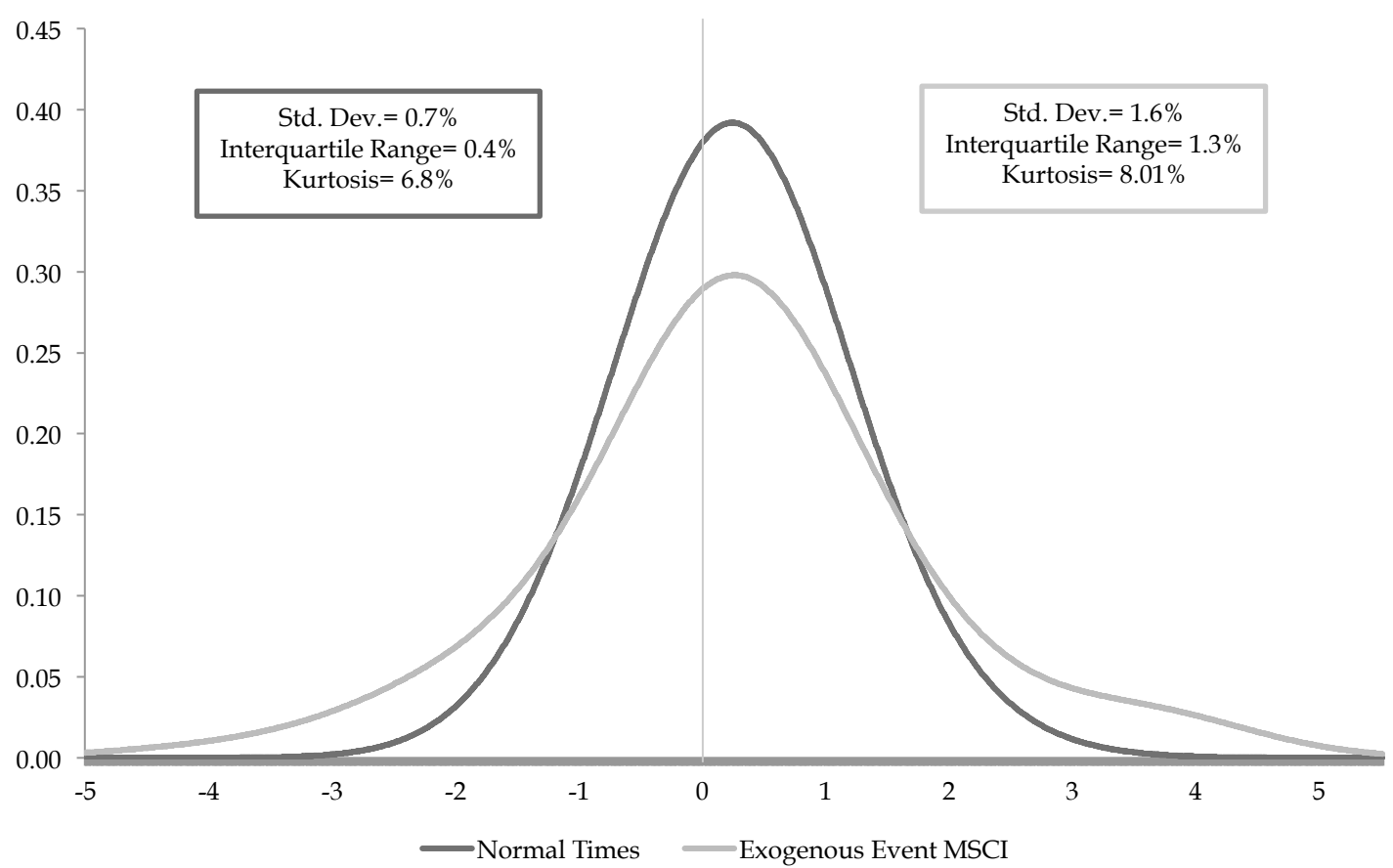




\section{Online Appendix Table 1 \\ Mutual Fund Summary Statistics}

This table shows summary statistics of equity and bond mutual funds from the joint Morningstar Direct/EPFR database. Funds are divided by degree of activism, type of fund, and according to the country in which the fund is based (domicile). When divided by domicile the category Others includes Andorra, Australia, Austria, Bahrain, Bermuda, British Virgin Islands, Cayman Islands, Estonia, Finland, Germany, Greece, Guernsey, Hong Kong, India, Isle of Man, Israel, Italy, Japan, Jersey, Liechtenstein, Lithuania, Mauritius, Netherlands, Netherlands Antilles, Norway, Portugal, Singapore, Slovenia, South Africa, South Korea, Spain, Sweden, Switzerland, the United Arab Emirates, and funds with unassigned domicile.

\section{A. Summary Statistics}

\begin{tabular}{lccccc}
\hline Type of Fund & Number of Funds & $\begin{array}{c}\text { Number of Observations } \\
\text { (Fund-Month) }\end{array}$ & $\begin{array}{c}\text { First Available } \\
\text { Date }\end{array}$ & $\begin{array}{c}\text { Last Available } \\
\text { Date }\end{array}$ & $\begin{array}{c}\text { Median Observations } \\
\text { per Fund (Months) }\end{array}$ \\
\hline Equity & 2,837 & 156,253 & January 1996 & July 2012 & 70 \\
Bond & 838 & 35,219 & March 1997 & June 2012 & 54 \\
\hline
\end{tabular}

B. Number of Funds and Observations by Different Attributes

\begin{tabular}{|c|c|c|c|c|c|}
\hline Degree of Activism & Number of Funds & $\begin{array}{c}\text { Number of Observations } \\
\text { (Fund-Month) }\end{array}$ & Type of Fund & Number of Funds & $\begin{array}{c}\text { Number of Observations } \\
\text { (Fund-Month) }\end{array}$ \\
\hline \multicolumn{6}{|c|}{ Equity Funds } \\
\hline Explicit Indexing & 85 & 3,420 & Global & 569 & 29,037 \\
\hline Closet Indexing & 939 & 50,906 & Global Emerging & 594 & 32,950 \\
\hline Mildly Active & 994 & 58,960 & Regional & 1,674 & 94,266 \\
\hline Truly Active & 819 & 42,967 & & & \\
\hline \multicolumn{6}{|c|}{ Bond Funds } \\
\hline Explicit Indexing & 21 & 588 & Global & 554 & 22,958 \\
\hline Closet Indexing & 54 & 2,851 & Global Emerging & 220 & 8,568 \\
\hline Mildly Active & 714 & 29,768 & Regional & 64 & 3,693 \\
\hline Truly Active & 49 & 2,012 & & & \\
\hline
\end{tabular}

C. Number of Funds and Observations by Domicile

\begin{tabular}{|c|c|c|c|c|c|}
\hline Domicile & Number of Funds & $\begin{array}{c}\text { Number of Observations } \\
\text { (Fund-Month) }\end{array}$ & Domicile & Number of Funds & $\begin{array}{c}\text { Number of Observations } \\
\text { (Fund-Month) }\end{array}$ \\
\hline \multicolumn{6}{|c|}{ Equity Funds } \\
\hline$\overline{\text { Belgium }}$ & 51 & 2,495 & Luxembourg & 348 & 22,360 \\
\hline Canada & 349 & 22,225 & United Kingdom & 225 & 16,615 \\
\hline Denmark & 85 & 4,995 & United States & 495 & 25,887 \\
\hline France & 158 & 6,206 & Others & 917 & 44,588 \\
\hline Ireland & 209 & 10,882 & & & \\
\hline
\end{tabular}

\section{Bond Funds}

\begin{tabular}{lcclcc}
\hline Denmark & 40 & 2,002 & Luxembourg & 31 & 1,700 \\
Germany & 35 & 1,421 & United Kingdom & 36 & 85 \\
Ireland & 56 & 2,314 & United States & 4,725 & 479 \\
Israel & 43 & 1,367 & Others & & \\
Italy & 33 & 953 & & \\
\hline
\end{tabular}


Online Appendix Table 2

\section{List of Benchmarks Used}

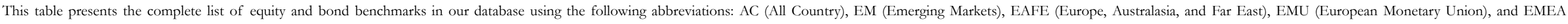
(Emerging Markets Europe, Middle East, and Africa). EMBI+, EMBI Global, and EMBI Global Diversified are bond benchmarks.

Equity and Bond Benchmarks

\begin{tabular}{|c|c|c|}
\hline $25 \%$ MSCI Brazil $+25 \%$ MSCI Russia+25\% MSCI India+25\% MSCI China & MSCI AC ASIA Pacific & MSCI Europe Small Cap \\
\hline $50 \%$ MSCI AC Far East + 50\% MSCI AC Far East ex-Japan & MSCI AC Asia Pacific Ex-Japan & MSCI Frontier Markets \\
\hline $50 \%$ MSCI Japan $+50 \%$ MSCI AC Asia-Pacific Free ex-Japan & MSCI AC Europe & MSCI GCC Ex Saudi Arabia \\
\hline $60 \%$ MSCI AC Asia Pacific ex-Japan + 40\% MSCI Japan & MSCI AC Far East & MSCI Pacific \\
\hline 75\% MSCI AC Far East Free ex-Japan + 25\% MSCI Japan & MSCI AC Far East Ex-Japan & MSCI Pacific Ex-Japan \\
\hline 75\% MSCI Arabian Markets ex Saudi Arabia + 25\% MSCI Saudi Arabian Domestic & MSCI AC Pacific & MSCI World \\
\hline 87\% MSCI Eastern Europe + 13\% MSCI Russia & MSCI AC Pacific Ex-Japan & MSCI World Small Cap \\
\hline Citigroup World Ex-US Extended & MSCI AC World & S\&P Asia $50 \mathrm{TR}$ \\
\hline DJ Asia Pac Select Dividend 30 & MSCI AC World Ex-US & S\&P BRIC 40 \\
\hline DJ Asia Pacific Selected Div 30 & MSCI AC World Investable Mkt & S\&P Citi BMI Emerging Markets \\
\hline DJ Asian Titans & MSCI Arabian Markets Ex-Saudi Arabia & S\&P Citi BMI European Em Capped \\
\hline DJ Global Titans 50 & MSCI BRIC & S\&P Citi EM EPAC \\
\hline Euro Stoxx & MSCI EAFE & S\&P Citi EMI Global \\
\hline Euro STOXX 50 & MSCI EAFE Small Cap & S\&P Citi PMI Eurozone Growth \\
\hline FTSE AW Eastern Europe & MSCI EM Asia & S\&P Citi PMI World Value \\
\hline FTSE RAFI Emerging Markets & MSCI EM Eastern Europe & S\&P Europe 350 \\
\hline FTSE World & MSCI EM Eastern Europe ex Russia & S\&P Global 100 \\
\hline FTSE World Asia Pacific & MSCI EM EMEA & S\&P IFC Investable \\
\hline FTSE World Eurobloc & MSCI EM Europe & S\&P IFC Investable Composite \\
\hline FTSE World Europe & MSCI EM Far East & S\&P IFCG Asia \\
\hline FTSE World Europe ex-UK & MSCI EM Latin America & S\&P IFCG Latin America \\
\hline FTSE World Pacific ex-Japan & MSCI Emerging Markets & S\&P IFCG Middle East \& Africa \\
\hline J.P. Morgan EMBI Global & MSCI Emerging Markets Europe+Middle East & S\&P IFCI Composite \\
\hline J.P. Morgan EMBI Global Diversified & MSCI EMU & S\&P IFC Investable Latin America \\
\hline J.P. Morgan EMBI+ & MSCI Europe & S\&P IFCI Latin America \\
\hline MSCI AC Asia Ex-Japan & MSCI Europe Ex-UK & S\&P Latin America 40 \\
\hline
\end{tabular}


Online Appendix Table 3

List of Direct Benchmark Effect Episodes

This table details all the episodes with significant benchmark changes due to upgrades/downgrades of countries. Panel A presents episodes from MSCI with upgrades and downgrades. Panel B shows all countries affected by the upgrade of Qatar and United Arab Emirates. Panel C details debt upgrades and downgrades from Barclays, Citigroup and J.P. Morgan. Panel D shows upgrades and downgrades from rating agencies.

\begin{tabular}{|c|c|c|c|c|c|c|c|}
\hline Country & Equity/Debt & Announcement Date & Effective Date & Change Type & From & To & Company \\
\hline \multicolumn{8}{|c|}{ A. Equity Upgrades/Downgrades } \\
\hline Argentina & Equity & Feb 19, 2009 & Jun 01, 2009 & Downgrade & EM & FM & MSCI \\
\hline Greece & Equity & Jun 12, 2013 & Dec 01, 2013 & Downgrade & $\mathrm{DM}$ & EM & MSCI \\
\hline Israel & Equity & Jun 16, 2009 & Jun 01, 2010 & Upgrade & EM & $\mathrm{DM}$ & MSCI \\
\hline Jordan & Equity & Jun 19, 2008 & Dec 01, 2008 & Downgrade & EM & FM & MSCI \\
\hline Morocco & Equity & Jun 12, 2013 & Dec 01, 2013 & Downgrade & EM & FM & MSCI \\
\hline Qatar & Equity & Jun 12, 2013 & Jun 01, 2014 & Upgrade & FM & EM & MSCI \\
\hline U.A.E. & Equity & Jun 12, 2013 & Jun 01, 2014 & Upgrade & FM & EM & MSCI \\
\hline \multicolumn{8}{|c|}{ B. Contagion Episode Qatar/UAE } \\
\hline Argentina & Equity & Apr 01, 2014 & Jun 01, 2014 & Upweight & FM & FM & MSCI \\
\hline Bahrain & Equity & Apr 01, 2014 & Jun 01, 2014 & Upweight & FM & FM & MSCI \\
\hline Bangladesh & Equity & Apr 01, 2014 & Jun 01, 2014 & Upweight & FM & FM & MSCI \\
\hline Estonia & Equity & Apr 01, 2014 & Jun 01, 2014 & Upweight & FM & FM & MSCI \\
\hline Jordan & Equity & Apr 01, 2014 & Jun 01, 2014 & Upweight & FM & FM & MSCI \\
\hline Kazakhstan & Equity & Apr 01, 2014 & Jun 01, 2014 & Upweight & FM & FM & MSCI \\
\hline Kenya & Equity & Apr 01, 2014 & Jun 01, 2014 & Upweight & FM & FM & MSCI \\
\hline Kuwait & Equity & Apr 01, 2014 & Jun 01, 2014 & Upweight & FM & $\mathrm{FM}$ & MSCI \\
\hline Mauritius & Equity & Apr 01, 2014 & Jun 01, 2014 & Upweight & FM & FM & MSCI \\
\hline Morocco & Equity & Apr 01, 2014 & Jun 01, 2014 & Upweight & FM & FM & MSCI \\
\hline Nigeria & Equity & Apr 01, 2014 & Jun 01, 2014 & Upweight & FM & FM & MSCI \\
\hline Oman & Equity & Apr 01, 2014 & Jun 01, 2014 & Upweight & FM & FM & MSCI \\
\hline Pakistan & Equity & Apr 01, 2014 & Jun 01, 2014 & Upweight & FM & $\mathrm{FM}$ & MSCI \\
\hline Romania & Equity & Apr 01, 2014 & Jun 01, 2014 & Upweight & FM & FM & MSCI \\
\hline Slovenia & Equity & Apr 01, 2014 & Jun 01, 2014 & Upweight & FM & FM & MSCI \\
\hline Sri Lanka & Equity & Apr 01, 2014 & Jun 01, 2014 & Upweight & FM & FM & MSCI \\
\hline Vietnam & Equity & Apr 01, 2014 & Jun 01, 2014 & Upweight & FM & FM & MSCI \\
\hline Qatar & Equity & Apr 01, 2014 & Jun 01, 2014 & Downweight & FM & FM & MSCI \\
\hline U.A.E. & Equity & Apr 01, 2014 & Jun 01, 2014 & Downweight & FM & FM & MSCI \\
\hline \multicolumn{8}{|c|}{ C. Episodes for Local Currency Denominated Debt } \\
\hline Hungary & Debt & Nov 05, 2013 & Nov 05, 2013 & Downgrade & Barclays GAI & Standalone & Barclays \\
\hline Israel & Debt & Oct 03,2011 & Jan 01, 2012 & Upgrade & Standalone & Barclays GAI & Barclays \\
\hline Malaysia & Debt & Nov 04, 2014 & Mar 31, 2015 & Upgrade & Standalone & Barclays GAI & Barclays \\
\hline Russia & Debt & Nov 05, 2013 & Mar 31, 2014 & Upgrade & Standalone & Barclays GAI & Barclays \\
\hline Taiwan & Debt & Oct 03,2011 & Jan 01, 2012 & Downgrade & Barclays GAI & Standalone & Barclays \\
\hline Turkey & Debt & Nov 05, 2013 & Mar 31, 2014 & Upgrade & Standalone & Barclays GAI & Barclays \\
\hline Mexico & Debt & Mar 31, 2010 & Oct 01, 2010 & Upgrade & Standalone & WGBI & Citigroup \\
\hline South Africa & Debt & Jun 10, 2012 & Oct 01, 2012 & Upgrade & Standalone & WGBI & Citigroup \\
\hline Colombia & Debt & Mar 19, 2014 & Oct 01, 2014 & Upweight & GBI & GBI & J.P. Morgan \\
\hline Nigeria & Debt & Aug 15, 2012 & Dec 01, 2012 & Upgrade & Standalone & GBI & J.P. Morgan \\
\hline Peru & Debt & Aug 03, 2015 & Nov 30, 2015 & Downgrade & GBI & Standalone & J.P. Morgan \\
\hline Romania & Debt & Jan 15, 2013 & May 01, 2013 & Upgrade & Standalone & GBI & J.P. Morgan \\
\hline Thailand & Debt & Oct 12,2010 & Sep 01, 2011 & Downweight & GBI & GBI & J.P. Morgan \\
\hline \multicolumn{8}{|c|}{ D. Investment and Non-Investment Grade Episodes } \\
\hline Brazil & Debt & - & Apr 29, 2008 & Upgrade & Non-Investment Grade & Investment Grade & S\&P \\
\hline Bulgaria & Debt & - & Jun 24, 2004 & Upgrade & Non-Investment Grade & Investment Grade & $S \& P$ \\
\hline Colombia & Debt & - & Aug 10, 1999 & Downgrade & Investment Grade & Non-Investment Grade & Fitch \\
\hline Colombia & Debt & - & Mar 16, 2011 & Upgrade & Non-Investment Grade & Investment Grade & S\&P \\
\hline Hungary & Debt & Nov 11, 2011 & Dec 21, 2011 & Downgrade & Investment Grade & Non-Investment Grade & S\&P \\
\hline Indonesia & Debt & - & Dec 15, 2011 & Upgrade & Non-Investment Grade & Investment Grade & Fitch \\
\hline Mexico & Debt & - & Jan 15, 2000 & Upgrade & Non-Investment Grade & Investment Grade & Fitch \\
\hline Peru & Debt & - & Apr 02, 2008 & Upgrade & Non-Investment Grade & Investment Grade & Fitch \\
\hline Philippines & Debt & - & Mar 26, 2013 & Upgrade & Non-Investment Grade & Investment Grade & Fitch \\
\hline Russia & Debt & Jul 28, 2003 & Oct 08,2003 & Upgrade & Non-Investment Grade & Investment Grade & Moody's \\
\hline South Korea & Debt & Dec 21, 1998 & Jan 19, 1999 & Upgrade & Non-Investment Grade & Investment Grade & Fitch \\
\hline Thailand & Debt & - & Jun 24, 1999 & Upgrade & Non-Investment Grade & Investment Grade & Fitch \\
\hline Turkey & Debt & - & Nov 05, 2012 & Upgrade & Non-Investment Grade & Investment Grade & Fitch \\
\hline Uruguay & Debt & - & Apr 03, 2012 & Upgrade & Non-Investment Grade & Investment Grade & S\&P \\
\hline
\end{tabular}




\section{Online Appendix Table 4}

\section{Capital Flows Variance Descomposition by Country}

This table presents the variance descomposition of capital flows from mutual funds into four components for different countries that were downgraded or upgraded from a benchmark index. Benchmark flows is the estimated alpha times benchmark weight multiplied by fund flows. Active flows is the difference between the weight and benchmark weight multiplied by the estimated alpha, times fund flows. Benchmark reallocation is the past assets multiplied by fund returns times the estimated alpha multiplied by the difference between the benchmark weight and the buy-and-hold benchmark weight. Active reallocation is the difference between the active weight and the active buy-and-hold weight multiplied by lagged assets times fund returns. For each exercise, we construct the total capital flows (and components) within each country-date. Then, we obtain the variance at the country level, imputing equally the covariances across the four components and we present the average and median share explained by each component.

\begin{tabular}{|c|c|c|c|c|c|c|}
\hline Sample & $\begin{array}{c}\text { Benchmark } \\
\text { Flows } \\
\end{array}$ & $\begin{array}{l}\text { Active } \\
\text { Flows } \\
\end{array}$ & $\begin{array}{c}\text { Benchmark } \\
\text { Reallocation } \\
\end{array}$ & $\begin{array}{c}\text { Active } \\
\text { Reallocation } \\
\end{array}$ & $\begin{array}{c}\text { Total Benchmark } \\
(1)+(3)\end{array}$ & $\begin{array}{c}\text { Total Active } \\
(2)+(4)\end{array}$ \\
\hline \multicolumn{7}{|c|}{ A. Argentina } \\
\hline All Funds & 6.8 & 2.3 & 35.5 & 55.4 & 42.3 & 57.7 \\
\hline Explicit Indexing & 17.2 & 0.6 & 47.5 & 34.8 & 64.7 & 35.3 \\
\hline Closet Indexing & 10.3 & 1.2 & 26.1 & 62.5 & 36.4 & 63.6 \\
\hline Mildly Active & 8.4 & 3.4 & 41.4 & 46.8 & 49.8 & 50.2 \\
\hline Truly Active & 0.9 & 6.7 & 3.4 & 89.0 & 4.3 & 95.7 \\
\hline
\end{tabular}

B. Colombia

\begin{tabular}{|c|c|c|c|c|c|c|}
\hline All Funds & 12.6 & 5.4 & 27.5 & 54.5 & 40.1 & 59.9 \\
\hline Explicit Indexing & 23.4 & 6.0 & 22.9 & 47.7 & 46.3 & 53.7 \\
\hline Closet Indexing & 13.6 & 5.4 & 18.4 & 62.6 & 32.0 & 68.0 \\
\hline Mildly Active & 7.1 & 3.6 & 19.6 & 69.8 & 26.7 & 73.3 \\
\hline Truly Active & 11.6 & 8.3 & 10.4 & 69.7 & 22.0 & 78.0 \\
\hline
\end{tabular}

\begin{tabular}{|c|c|c|c|c|c|c|}
\hline \multicolumn{7}{|c|}{ C. Israel } \\
\hline All Funds & 3.6 & 1.2 & 62.9 & 32.3 & 66.5 & 33.5 \\
\hline Explicit Indexing & 4.6 & 0.7 & 88.7 & 6.0 & 93.3 & 6.7 \\
\hline Closet Indexing & 6.6 & 1.7 & 54.6 & 37.0 & 61.2 & 38.8 \\
\hline Mildly Active & 7.4 & 3.3 & 43.9 & 45.3 & 51.4 & 48.6 \\
\hline Truly Active & 3.0 & 2.4 & 44.3 & 50.4 & 47.3 & 52.7 \\
\hline
\end{tabular}

D. Venezuela

\begin{tabular}{lcccccc}
\hline All Funds & 7.5 & 2.6 & 39.1 & 50.7 & 46.7 & 53.3 \\
Explicit Indexing & 0.8 & 0.4 & 45.0 & 53.8 & 45.8 & 49.7 \\
Closet Indexing & 12.6 & 3.8 & 37.1 & 46.5 & 50.3 \\
Mildly Active & 9.7 & 3.2 & 31.6 & 55.5 & 51.3 \\
Truly Active & 1.4 & 15.9 & 10.2 & 72.5 & 11.6 \\
\hline
\end{tabular}

